\title{
Cross-subsidization in employer-based health insurance and the effects of tax subsidy reform *
}

\author{
Svetlana Pashchenko ${ }^{\dagger}$ \\ University of Georgia
}

\author{
Ponpoje Porapakkarm \\ National Graduate Institute \\ for Policy Studies
}

March 19, 2016

\begin{abstract}
A major source of insurance coverage for non-elderly adults in the US is the employer-based health insurance market. Every participant in this market receives a tax subsidy because premiums are excluded from taxable income. However, people have different incentives to participate in the employer-based pool - since premiums are independent of individual risk, high-risk individuals receive implicit cross-subsidies from low-risk individuals. In this paper, we explore several ways to reform the tax subsidy by taking this implicit crosssubsidization into account. Using a general equilibrium heterogeneous agents model, we find that even though the complete elimination of the tax subsidy leads to the unraveling of the employer-based pool, there is still room for substantial savings by targeting the tax subsidy. More specifically, the same level of risk-sharing in the employer-based market can be achieved at onethird of the current costs if i) the tax subsidy is targeted only towards lowrisk individuals who have weak incentives to participate in the pool, and ii) employer-based insurance premiums become age-adjusted. To improve the welfare outcome of this reform, the modified tax subsidy should also be targeted to low-income individuals.
\end{abstract}

Keywords: tax reform, tax subsidies, employer-based health insurance

JEL Classification Codes: D91, E65, H24

${ }^{*}$ We thank William Gentry, Joel Slemrod, George Zodrow, two anonymous referees and all seminar participants at the GRIPS, ASSA meeting in Philadelphia, the Midwest Macro Meeting, NASM in Minneapolis, and the SED in Seoul for their comments and suggestions.

${ }^{\dagger}$ Email: svetlana@uga.edu

${ }_{\ddagger}^{\ddagger}$ Email: p-porapakkarm@grips.ac.jp 


\section{Introduction}

Most non-elderly adults in the US (63\%) purchase health insurance in the employerbased market. ${ }^{1}$ An important feature of this market is community rating, i.e., the insurance premiums are independent of the health and age of individuals. ${ }^{2}$ For the communityrated market to provide good risk-sharing, there should be a significant number of healthy people who are willing to participate. In the employer-based market, an important incentive to participate is provided by tax subsidies: employer-based premiums are excluded from federal and state taxes. However, these subsidies are costly: CBO (2015) estimates that in 2013, the total federal cost of the tax exclusion was $\$ 250$ billion, making it the largest tax expenditures by the federal government and the third largest expenditure on health care after Medicare ( $\$ 586$ billion) and Medicaid and CHIP ( $\$ 463$ billion). ${ }^{3}$

In this paper, we ask whether it is possible to reduce spending on tax subsidies without destroying the employer-based pool. Our question is motivated by the observation that every participant in the employer-based market receives a tax subsidy, but people have different incentives to participate in this pool. The employer-based pool involves sizeable cross-subsidization from people with low expected medical costs (young and healthy) to people with high expected medical costs (old and unhealthy). The former group pays more, and the latter group pays less for their health insurance than they would pay if insurance premiums are adjusted for individual risks. As a consequence, people with high expected medical costs have stronger incentives than people with low expected medical costs to join the pool. Based on this observation, we explore several ways to better target tax subsidies and evaluate the effects of these alternative subsidy schemes on tax expenditures and risk-pooling in the employer-based market.

Our approach is based on a quantitative heterogeneous agents model developed by

\footnotetext{
${ }^{1}$ Own calculations based on the Medical Expenditure Panel Survey (MEPS) dataset.

${ }^{2}$ In this paper, we refer to community rating in the employer-based market to describe the health insurance pricing within the pool of people insured by employer-based insurance. It is important to distinguish it from the community rating for employers. The latter refers to the situation in which different employers face the same price for insuring their workers (for example, because they are in the same geographical region). Another pricing scheme for employers is experience rating, a situation in which the insurance price depends on the previous history of claims. It is important to note that even employers who face the experience rating still have to charge all their workers the same insurance premium (as long as they buy the same plan), i.e., they cannot introduce the experience rating to the ESHI pool.

${ }^{3}$ As defined in the Congressional Budget and Impoundment Control Act of 1974, tax expenditures are "revenue losses attributable to provisions of the Federal tax laws which allow a special exclusion, exemption, or deduction from gross income or which provide a special credit, a preferential rate of tax, or a deferral of tax liability." Tax expenditures usually are calculated with reference to the normal tax structure. Joint Committee on Taxation defines the normal structure of the individual income tax as the existing tax rate schedule with several standard deductions and exemptions. Apart from these standard deductions, all other tax benefits (including tax subsidy for employer-based health insurance) are classified as special provisions (JCT, 2015). Thus, tax expenditures are calculated as the difference in tax revenue between the normal tax structure and the tax structure with special provisions.
} 
Pashchenko and Porapakkarm (2013). The model features medical spending shocks that can be insured through the individual or employer-based markets. An important difference between these two markets is that in the former, the premiums are risk-adjusted, whereas in the latter there is a community-rating, meaning that healthy and unhealthy people are charged the same premium. People are heterogeneous in their expected medical costs, which creates different incentives to participate in the community-rated market: people with low expected costs may prefer to buy risk-adjusted insurance (or self-insure), while people with high expected costs may prefer to participate in the community-rated pool. The model also captures the differential treatment of health insurance embedded in the tax code: employer-based premiums are excluded from taxable income, while individual market premiums are not. The calibrated model reproduces the key aggregate statistics for the US, as well as the empirical life-cycle patterns of employment and insurance coverage constructed based on the Medical Expenditure Panel Survey (MEPS) dataset.

Our findings are as follows. First, we show that if tax exclusion is substituted by a direct subsidy that is targeted only at people with weak incentives to participate in the employer-based pool, the costs of subsidizing people with employer-based insurance can be decreased by $74 \%$ without any damage to the risk-sharing. To achieve this outcome, the amount of the direct subsidy should depend on the risk-adjusted premium of each individual. Even higher cost savings can be achieved if premiums in the group market become age-adjusted, i.e., premiums can vary with age (but not with health). Since medical costs increase quickly with age, community rating involves a sizeable cross-subsidization from the young to the old. Therefore, a large amount of direct subsidies is needed to motivate young people to participate in this pool. Allowing the premiums to be age-adjusted reduces the size of cross-subsidization inside the pool, thus decreasing the amount of direct subsidies needed to hold the pool together.

Second, using results from the direct subsidy scheme, we explore how to reform the current tax exclusion in order to obtain a similar outcome. We find that the reform that maintains good risk-sharing in the employer-based pool while significantly reducing the tax expenditures consists of two steps: i) allowing the premiums in the employer-based market to be age-adjusted, and ii) giving tax subsidies only to those participants of the employer-based pool who currently have low medical spending. ${ }^{4}$ Under this reform, the spending on the tax subsidy constitutes only a third (34.6\%) of the amount in the baseline economy and the tax rate decreases by one percentage point, while the take-up rate of the employer-based insurance slightly increases (97.1\% compared with $94.2 \%$ in the baseline). In contrast, if tax subsidy is completely eliminated, the take-up rate goes

\footnotetext{
${ }^{4}$ Since medical expenditures are persistent, people with low current medical expenses have lower expected expenses; thus, they drive down the average premium in the employer-based market.
} 
down to $6.3 \%$. We repeat the analysis assuming that the health reform described in the Affordable Care Act (ACA) is implemented and find that the proposed tax subsidy reform achieves a similar outcome in terms of the ESHI take-up rate and the reduction in the total tax subsidy costs. ${ }^{5}$

Finally, our welfare analysis shows that the proposed tax subsidy reform achieves much higher welfare gains if low-income individuals (those with income below $200 \%$ of the Federal Poverty Line) are also allowed to keep the tax subsidy. ${ }^{6}$ This is because the best risk-pooling is achieved when tax subsidies are targeted at low-risk individuals, whereas the best welfare outcomes are achieved when tax subsidies are targeted at lowincome individuals.

Several studies examine the effects of the tax exclusion reform, but none of them investigates the possibilities of targeting the tax subsidy. Gruber (2011) uses a microsimulation model to evaluate the effect of tax exclusion removal and finds that this reform substantially increases government revenue yet significantly decreases insurance coverage. Aizawa and Fang (2012) focus on firms' decisions to offer health insurance and find that removal of the tax exclusion slightly reduces the number of firms offering employer-based insurance. The closest paper to ours is that by Jeske and Kitao (2009), who address this question using a stochastic aging general equilibrium model featuring individuals who are heterogeneous in their medical expense shocks. They find that eliminating the tax exclusion results in a partial collapse of the employer-based market due to the adverse selection problem. Similar to Jeske and Kitao (2009), we focus on individual decisions related to health insurance but allow for a full life cycle. Because the difference in expected medical expenses between the young and the old is large, the premium in the employer-based market is very sensitive to the age composition of the pool, and thus, the full life-cycle can better capture the risk of the unravelling of the market.

More generally, we contribute to the literature that examines the implications of government policies related to health and the health insurance market. This literature

\footnotetext{
${ }^{5}$ It is important to draw a parallel between our proposed policy and the ACA: we suggest introducing age-adjusted community rating in the group market while the ACA did the same for the individual insurance market. The question of whether premiums in the individual market should be common for all participants or be allowed to vary by age was among the debatable ones before the passage of the ACA. One of the rationales for choosing the latter option in the final bill was that expected medical costs (and thus insurance costs) are steeply increasing with age, thus making the young and the old pay the same premium involves considerable cross-subsidization from the former group to the latter. Given that older individuals usually have higher income and have accumulated more assets, this cross-subsidization is not necessarily optimal. The same reasoning applies to our policy proposal. Given that the ACA was passed, we believe that our proposal also is politically feasible. It is also worth stressing out the important difference from the practice in the European countries which sometime is used as an argument against the age-adjustment. In most European countries health insurance is universal and financed by income or payroll taxes. There are no explicit age-adjusted premiums, but since income increases with age, older people on average pay more into the insurance system.

${ }^{6}$ We use utilitarian criterion in our welfare analysis.
} 
includes Attanasio, Kitao and Violante (2011), Hai (2012), Hansen et al. (2014), Kim (2012), Ozkan (2012), Hsu (2013), St-Amour (2012), and Zhao (2014). We also relate to the literature that studies the life-cycle behavior of individuals in the presence of health uncertainty, such as Capatina (2014), De Nardi et al. (2010), French and Jones (2011), Kopecky and Koreshkova (2013), and Prados (2012).

The paper is organized as follows. Section 2 describes a simple model that illustrates the intuition behind our results. Section 3 introduces the full model. Section 4 describes our calibration. Section 5 evaluates the performance of the baseline model. Section 6 describes the results. Section 7 concludes.

\section{Simple Model}

In this section, we construct a simple model to illustrate the intuition behind our results. In this simple framework, we show how different subsidy schemes can be used to keep together an insurance pool of individuals who are heterogeneous in their risks.

Consider a continuum of individuals who differ in their expected medical costs. We denote an actuarial fair insurance price of an individual $i$ by $p_{i}$. Assume $p_{i}$ is uniformly distributed over the interval $\left[0, p_{H}\right], p_{i} \sim F(p)$. If all individuals participate in one insurance pool, the price in this pool will be equal to $\bar{p}=\int_{0}^{p_{H}} p d F(p)=\frac{p_{H}}{2}$. However, this pool is unstable because individuals with $p_{i}<\bar{p}$ want to drop out. ${ }^{7}$ To prevent the unraveling, we need to introduce subsidies. First, we consider the case in which the size of the subsidy cannot be differentiated, i.e., every individual receives the same subsidy $s$. To ensure full participation, the subsidy must be equal to $\bar{p}$ to make an individual with the lowest $p_{i}=0$ indifferent between staying or leaving, i.e., $s=\bar{p}$. The total spending on subsidies $\left(\operatorname{Tot}_{\mathrm{S} u b s}\right)$ is equal to

$$
\operatorname{TotSubs}_{1}=\int_{0}^{p_{H}} s d F(p)=\frac{p_{H}^{2}}{2}
$$

This is graphically represented by the shaded rectangle in Figure 1.

Second, consider the situation in which the size of the subsidy can be differentiated. In this case, each individual receives a subsidy $s_{i}=\max \left\{0, \bar{p}-p_{i}\right\}$. Thus, only individuals with $p_{i}<\bar{p}$ will receive the subsidy, and the size of the subsidy decreases in $p_{i}$. The total

\footnotetext{
${ }^{7}$ We assume that individuals are free to buy health insurance at risk-adjusted actuarially fair prices. In our quantitative model, we relax this assumption by introducing a mark-up on individual insurance.
} 
spending on subsidies is equal to

$$
\operatorname{TotSubs}_{2}=\int_{0}^{p_{H}} s_{i} d F(p)=\frac{p_{H}^{2}}{8} .
$$

This is graphically represented by the shaded triangle in Figure 2. Note that the total spending on subsidies can be reduced by four times by taking into account that individuals differ in their incentives to participate in the pool.

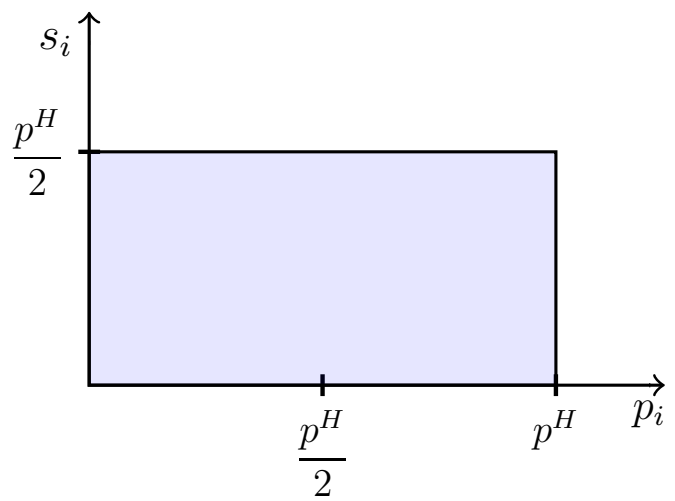

Figure 1: Total subsidy spending if everyone re- Figure 2: Total subsidy spending if subsidy deceives the same subsidy

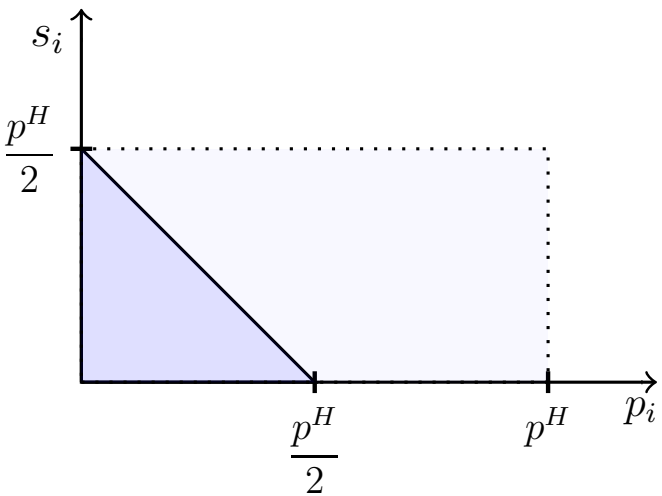

pends on $p_{i}$

To illustrate the importance of pool heterogeneity for subsidy spending, consider another example. Assume that there are two insurance pools instead of one: people with $p_{i}<\bar{p}$ participate in the first pool, and people with $p_{i} \geq \bar{p}$ participate in the second. The prices in the first pool $\left(\bar{p}_{1}\right)$ and in the second pool $\left(\bar{p}_{2}\right)$ are equal to $\frac{p_{H}}{4}$ and $\frac{3 p_{H}}{4}$, respectively. ${ }^{8}$

Consider the total subsidy spending needed to ensure full participation in each pool. If the subsidy is uniform, every individual in the first pool should receive a subsidy equal to $\bar{p}_{1}-0=\frac{p_{H}}{4}$, and those in the second pool should receive $\bar{p}_{2}-\bar{p}=\frac{p_{H}}{4}$. Thus, the total spending needed to keep the pools together is:

$$
\operatorname{TotSubs}_{3}=\frac{p_{H}}{4} \int_{0}^{\bar{p}} d F(p)+\frac{p_{H}}{4} \int_{\bar{p}}^{p_{H}} d F(p)=\frac{p_{H}^{2}}{4}
$$

This is graphically represented by the two small shaded rectangles in Figure 3.

\footnotetext{
${ }^{8}$ These prices are determined in the following way:
}

$$
\bar{p}_{1}=\frac{1}{\operatorname{Pr}(p<\bar{p})} \int_{0}^{\bar{p}} p d F(p)=\frac{p_{H}}{4} \quad \text { and } \quad \bar{p}_{2}=\frac{1}{\operatorname{Pr}(p \geq \bar{p})} \int_{\bar{p}}^{p_{H}} p d F(p)=\frac{3 p_{H}}{4} .
$$


In case of the differentiated subsidy, people in the first pool receive a subsidy equal to $s_{i}^{1}=\max \left\{0, \bar{p}_{1}-p_{i}\right\}$ and people in the second pool, $s_{i}^{2}=\max \left\{0, \bar{p}_{2}-p_{i}\right\}$. The total spending on subsidies is equal to

$$
\text { TotSubs }_{4}=\int_{0}^{\bar{p}} s_{i}^{1} d F(p)+\int_{\bar{p}}^{\bar{p}_{H}} s_{i}^{2} d F(p)=\frac{p_{H}^{2}}{16}
$$

This is graphically represented by the two shaded triangles in Figure 4.

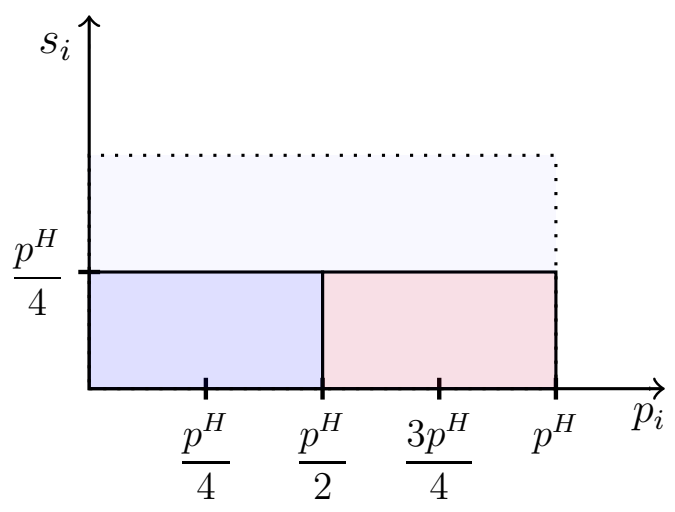

Figure 3: Total subsidy spending if there are two insurance pools and everyone receives the same subsidy

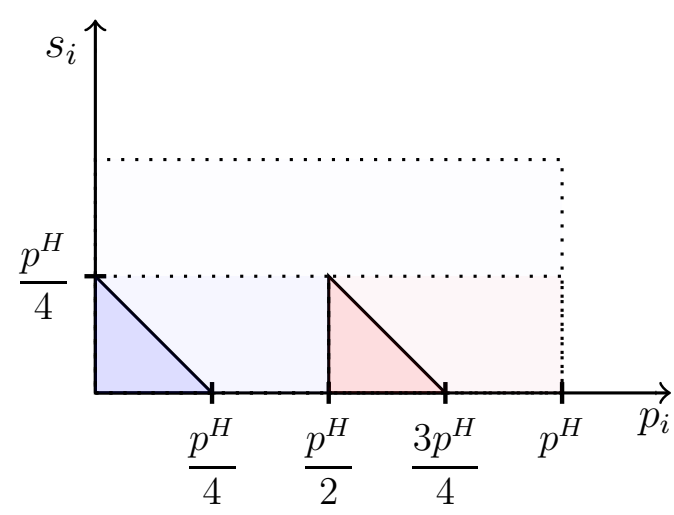

Figure 4: Total subsidy spending if there are two insurance pools and subsidy depends on $p_{i}$

Table 1 summarizes the total subsidy spending in the four cases considered above. An important result is that moving from the uniform to differentiated subsidy can substantially reduce the total spending needed to ensure the full participation in the pool. These savings arise from withdrawing subsidies from people who are willing to participate even when they are not subsidized, i.e., people with $p_{i}>\bar{p}$. Another result is that it is much cheaper to ensure full participation if there are two smaller insurance pools instead of one large pool. This is because in the two smaller pools, people are less heterogeneous in their risks; thus, the size of cross-subsidization from low risk to high risk is smaller. In particular, in the one large pool, the difference in risk-adjusted premiums between the highest and the lowest risks is $p_{H}$, whereas in the two smaller pools, it is $\bar{p}=p_{H}-\bar{p}=\frac{p_{H}}{2}$. Therefore, a smaller direct subsidy is needed to make low-risk individuals willing to cross-subsidize high-risk individuals. ${ }^{9}$

\footnotetext{
${ }^{9}$ Note that as the number of pools keeps increasing, the size of subsidies required to keep the pools together decreases, but the amount of risk-sharing achieved in each pool decreases as well. As the number of pools approaches the number of people, everyone simply faces risk-adjusted price.
} 


\begin{tabular}{|c|c|c|}
\hline & One pool & Two pools \\
\hline Uniform subsidy & $p_{H}^{2} / 2$ & $p_{H}^{2} / 4$ \\
Differentiated subsidy & $p_{H}^{2} / 8$ & $p_{H}^{2} / 16$ \\
\hline
\end{tabular}

Table 1: Total spending on subsidies for different subsidy schemes

\section{Baseline Model}

The model described in this section is developed by Pashchenko and Porapakkarm (2013). Here and in Section 4, we outline the main features of the model and its calibration; we refer the reader to Pashchenko and Porapakkarm (2013) for a more detailed description.

\section{$3.1 \quad$ Households}

\subsubsection{Demographics and preferences}

The economy is populated by overlapping generations of individuals. An individual lives to a maximum of $N$ periods. During the first $R-1$ periods of life, an individual can choose whether to work; at age $R$, all individuals retire. The labor supply decision of a household is denoted by $l_{t}, l_{t} \in\{0, \bar{l}\}$. Agents differ in their educational attainment $e$. Educational attainment can take two values: $e=1$ corresponds to the absence of any degree, whereas $e=2$ corresponds to at least a high-school degree.

Each agent is endowed with one unit of time that can be used for either leisure or work. There is a fixed cost of work $\phi_{t, e}$ treated as a loss of leisure. Thus, a working individual's leisure time can be expressed as $1-\bar{l}-\phi_{t, e}$. The fixed cost of work depends on age $(t)$ and education $(e)$. In addition, individuals in bad health incur higher costs of work: $\phi_{t, e}=\phi_{1}(t, e)+\phi_{2}(t, e) \mathbf{1}_{\{\text {health=bad\} }}$, where $\mathbf{1}_{\{.\}}$is an indicator function mapping to one if its argument is true, and $\phi_{1}(t, e)$ and $\phi_{2}(t, e)$ are non-negative functions. Earnings are equal to $\widetilde{w} z_{t}^{e, x} l_{t}$, where $\widetilde{w}$ is wage and $z_{t}^{e, x}$ is the idiosyncratic productivity that depends on the educational level $(e)$, age $(t)$ and medical expenses $\left(x_{t}\right)$ of an individual.

The preferences over consumption and leisure are assumed to take Cobb-Douglas form:

$$
u\left(c_{t}, l_{t}\right)=\frac{\left(c_{t}^{\chi}\left(1-l_{t}-\phi_{t, e} \mathbf{1}_{\left\{l_{t}>0\right\}}\right)^{1-\chi}\right)^{1-\sigma}}{1-\sigma} .
$$

Here, $\chi$ is a parameter that determines the relative importance of consumption, and $\sigma$ is the risk-aversion over the consumption-leisure composite.

Agents discount the future at the rate $\beta$ and survive until the next period with conditional probability $\zeta_{t}$, which depends on age and health. The savings (net of out-ofpocket medical expenses) of each household that does not survive are equally allocated 
among all survived agents of a working age within the same educational group. The population grows at the rate $\eta$.

\subsubsection{Health expenditures and health insurance}

In each period an agent faces a stochastic medical expenditure shock $x_{t}$, which evolves according to a 5 -state discrete Markov process $\mathcal{G}\left(x_{t+1} \mid x_{t}, t\right)$. More specifically, $x_{t}=1$ corresponds to the average spending at the bottom $30 \%$ of the medical expense distribution at age $t, x_{t}=2,3,4$ correspond to the average spending among 30th-60th, 60th-90th and 90th-99th percentiles respectively, and $x_{t}=5$ corresponds to the average spending of people at the top $1 \%$ of the distribution at age $t .{ }^{10}$ Individuals are categorized into two groups based on their medical expenses. Individuals with low medical expenses $\left(x_{t} \leq \overline{x_{t}}\right)$ are referred to as "healthy" or "people in good health", whereas individuals with high medical expenses $\left(x_{t}>\overline{x_{t}}\right)$ are referred to as "unhealthy" or "people in bad health". Here $\overline{x_{t}}$ is a threshold separating people into these two groups and corresponds to the 90th percentile of the medical spending distribution. ${ }^{11}$

Every working age individual can buy health insurance (HI) against a medical shock in the individual health insurance market. The price of health insurance in the individual market is a function of the agent's current medical shock and age and is denoted by $p_{I}\left(x_{t}, t\right)$.

In each period with some probability $\mathrm{Prob}_{t}$ an agent of working age receives an offer to buy employer-sponsored health insurance (ESHI). The variable $g_{t}$ characterizes the status of the offer: $g_{t}=1$ if an individual gets an offer, and $g_{t}=0$ if he does not. All participants in the employer-based pool are charged the same premium $p$ regardless of their current medical expenses and age. An employer pays a fraction $\psi$ of this premium. If the worker chooses to buy group insurance, he only pays $\bar{p}$ where:

$$
\bar{p}=(1-\psi) p
$$

Low-income individuals of working age can obtain their health insurance from Medicaid for free. There are two pathways to qualify for Medicaid. First, an individual can become eligible if his total income is below threshold $y^{\text {cat }}$. Second, an individual can become eligible through the Medically Needy program. This happens if his total income minus medical expenses is below threshold $y^{\text {need }}$, and his assets are less than the limit $k^{p u b}$.

\footnotetext{
${ }^{10}$ We explain more in Section A.2 in the Appendix.

${ }^{11}$ In the data, the fraction of workers among people with high medical expenses (top $10 \%$ of the distribution conditional on age) is much lower than this fraction among people with low medical expenses. We use health category defined in the text to capture this observation when we estimate the preference parameters $\phi_{t, e}$.
} 
The current health insurance status is denoted by $i_{t}$ :

$$
i_{t}=\left\{\begin{array}{ll}
0 & ; \text { if uninsured } \\
1 & ; \text { if insured by Medicaid } \\
2 & ; \text { if privately insured }
\end{array}\right\}
$$

All types of insurance contracts - group, individual, and public - provide only partial insurance against medical expenditure shocks. The fraction of medical expenditures covered by the insurance contract is denoted by $q\left(x_{t}, i_{t}\right)$. This fraction is a function of medical expenditures and the type of insurance of a household.

All retired households are enrolled in the Medicare program. The Medicare program charges a fixed premium of $p_{\text {med }}$ and covers a fraction $q_{m e d}$ of medical costs.

\subsubsection{Taxation and social transfers}

All households pay an income tax that consists of two parts: a progressive tax denoted by $\mathcal{T}\left(y_{t}\right)$ and a proportional tax denoted by $\tau_{y} .{ }^{12}$ The taxable income $y_{t}$ is based on both labor and capital income. Working households also pay payroll taxes, namely, Medicare $\operatorname{tax}\left(\tau_{\text {med }}\right)$ and Social Security tax $\left(\tau_{s s}\right)$. The Social Security tax rate for earnings above $\bar{y}_{s s}$ is zero. The US tax code allows each household to subtract out-of-pocket medical expenditures that exceed $7.5 \%$ of their income when the taxable income is calculated. In addition, the ESHI premium $(\bar{p})$ is excluded from the taxable income for both income and payroll taxes. Consumption is taxed at a proportional rate $\tau_{c}$.

There is also a public safety-net program, $T_{t}^{S I}$. The program guarantees that every household will have a minimum consumption level at $\underline{c}$. This reflects the option available to U.S. households with a bad combination of income and medical shocks to rely on public transfer programs such as food stamps, Supplemental Security Income, and uncompensated care. Retired households receive Social Security benefits $s s_{e}$ that depend on educational attainment $e$.

\subsubsection{Optimization problem}

Working age households $(t<R) \quad$ The state variables for the working age household's optimization problem are capital $\left(k_{t} \in \mathbb{K}=R^{+} \cup\{0\}\right)$, medical cost shock $\left(x_{t} \in \mathbb{X}=R^{+} \cup\{0\}\right)$, idiosyncratic labor productivity $\left(z_{t}^{e, x} \in \mathbb{Z}=R^{+}\right)$, ESHI offer status $\left(g_{t} \in \mathbb{G}=\{0,1\}\right)$, health insurance status $\left(i_{t} \in \mathbb{I}=\{0,1,2\}\right)$, educational attainment $(e \in \mathbb{E}=\{1,2\})$ and age $(t)$.

In each period, a household chooses consumption $\left(c_{t}\right)$, labor supply $\left(l_{t}\right)$, savings $\left(k_{t+1}\right)$, and health insurance status for the next period $\left(i_{H}^{\prime}\right)$. If an individual is eligible

\footnotetext{
${ }^{12}$ The progressive part $\mathcal{T}\left(y_{t}\right)$ approximates the actual income tax schedule in the U.S., whereas the proportional tax represents all other taxes that are not modeled explicitly.
} 
for Medicaid, he can receive free public insurance (option $M$ ). If he works in a firm offering ESHI, he can buy a group insurance $(G)$. In addition, everyone can choose to be uninsured $(U)$, or buy individual insurance $(I)$. These choices can be summarized as follows. If an individual is eligible for Medicaid:

$$
i_{H}^{\prime}=\left\{\begin{array}{ll}
\{M, I, G\} & \text { if } g_{t}=1 \text { and } l_{t}>0 \\
\{M, I\} & ; \text { if } g_{t}=0 \text { or } l_{t}=0
\end{array}\right\} .
$$

Otherwise

$$
i_{H}^{\prime}=\left\{\begin{array}{ll}
\{U, I, G\} & ; \text { if } g_{t}=1 \text { and } l_{t}>0 \\
\{U, I\} & ; \text { if } g_{t}=0 \text { or } l_{t}=0
\end{array}\right\} .
$$

The value function of a working-age individual can be written as follows:

$$
V_{t, e}\left(k_{t}, x_{t}, z_{t}^{e, x}, g_{t}, i_{t}\right)=\max _{k_{t+1}, c_{t}, l_{t}, i_{H}^{\prime}} u\left(c_{t}, l_{t}\right)+\beta \zeta_{t} E_{t} V_{t+1, e}\left(k_{t+1}, x_{t+1}, z_{t+1}^{e, x}, g_{t+1,} i_{t+1}\right)
$$

subject to

$$
\begin{aligned}
& k_{t}(1+r)+\widetilde{w} z_{t}^{e, x} l_{t}+T_{t}^{S I}+B e q_{e}=\left(1+\tau_{c}\right) c_{t}+k_{t+1}+x_{t}\left(1-q\left(x_{t}, i_{t}\right)\right)+P_{t}+\operatorname{Tax} \\
& \widetilde{w}=\left\{\begin{array}{lll}
w & ; & \text { if } g_{t}=0 \\
\left(w-c_{E}\right) & ; & \text { if } g_{t}=1
\end{array}\right\} \\
& P_{t}=\left\{\begin{array}{cll}
0 & ; & \text { if } i_{H}^{\prime} \in\{U, M\} \\
p_{I}\left(x_{t}, t\right) & ; & \text { if } i_{H}^{\prime}=I \\
\bar{p} & ; & \text { if } i_{H}^{\prime}=G
\end{array}\right\} \\
& i_{t+1}=\left\{\begin{array}{l}
0 ; \text { if } i_{H}^{\prime}=U \\
1 ; \text { if } i_{H}^{\prime}=M \\
2 ; \text { if } i_{H}^{\prime} \in\{I, G\}
\end{array}\right\} \\
& \text { Tax }=\mathcal{T}\left(y_{t}\right)+\tau_{y} y_{t}+\tau_{\text {med }}\left(\widetilde{w} z_{t}^{e, x} l_{t}-\bar{p} \mathbf{1}_{\left\{i_{H}^{\prime}=G\right\}}\right)+\tau_{s s} \min \left(\widetilde{w} z_{t}^{e, x} l_{t}-\bar{p} \mathbf{1}_{\left\{i_{H}^{\prime}=G\right\}}, \bar{y}_{s s}\right) \\
& y_{t}=r k_{t}+\widetilde{w} z_{t}^{e, x} l_{t}-\bar{p} \mathbf{1}_{\left\{i_{H}^{\prime}=G\right\}}-\max \left(0, x_{t}\left(1-q\left(x_{t}, i_{t}\right)\right)-0.075\left(\widetilde{w} z_{t}^{e, x} l_{t}+r k_{t}\right)\right) \\
& T_{t}^{S I}=\max \left(0,\left(1+\tau_{c}\right) \underline{c}+x_{t}\left(1-q\left(x_{t}, i_{t}\right)\right)+\operatorname{Tax}-\widetilde{w} z_{t}^{e, x} l_{t}-k_{t}(1+r)-B e q_{e}\right) .
\end{aligned}
$$

An individual is eligible for Medicaid if

$$
\left\{\begin{array}{c}
y_{t}^{\text {tot }} \leq y^{\text {cat }} \quad \text { or } \\
y_{t}^{\text {tot }}-x_{t}\left(1-q\left(x_{t}, i_{t}\right)\right) \leq y^{\text {need }} \text { and } k_{t} \leq k^{p u b}
\end{array}\right\}
$$


The conditional expectation on the right-hand side of Equation (3) is over $\left\{x_{t+1}, z_{t+1}^{e, x}, g_{t+1}\right\}$. Equation (4) is the budget constraint and $B e q_{e}$ is accidental bequest. In Equation (5), $w$ is wage per effective labor unit. If the household has an ESHI coverage, his employer pays a part of his insurance premium. The employer that offers ESHI passes these costs onto the employees by deducting an amount $c_{E}$ from the wage per effective labor unit, as shown in (5). ${ }^{13}$ Equation (7) maps the current HI choice into the next period HI status. In Equation (8), the first two terms are income taxes and the last two terms are payroll taxes. Note that contributions by both the employer and employee toward the ESHI premium are excluded from the taxable income.

Retired households For a retired household $(t \geq R)$, the state variables are capital $\left(k_{t}\right)$, medical expenses shock $\left(x_{t}\right)$, educational attainment $(e)$, and age $(t) .{ }^{14}$

$$
V_{t, e}\left(k_{t}, x_{t}\right)=\max _{k_{t+1}, c_{t}} u\left(c_{t}, 0\right)+\beta \zeta_{t} E_{t} V_{t+1, e}\left(k_{t+1}, x_{t+1}\right)
$$

subject to

$$
\begin{gathered}
k_{t}(1+r)+s s_{e}+T_{t}^{S I}=\left(1+\tau_{c}\right) c_{t}+k_{t+1}+x_{t}\left(1-q_{\text {med }}\right)+p_{\text {med }}+\text { Tax } \\
\operatorname{Tax}=\mathcal{T}\left(y_{t}\right)+\tau_{y} y_{t} \\
y_{t}=r k_{t}+s s_{e}-\max \left(0, x_{t}\left(1-q_{\text {med }}\right)-0.075\left(s s_{e}+r k_{t}\right)\right) \\
T_{t}^{S I}=\max \left(0,\left(1+\tau_{c}\right) \underline{c}+x_{t}\left(1-q_{\text {med }}\left(x_{t}\right)\right)+\text { Tax }+p_{\text {med }}-s s_{e}-k_{t}(1+r)\right) .
\end{gathered}
$$

Distribution of households To simplify the notation, let $\mathbb{S}$ define the space of a household's state variables, where $\mathbb{S}=\mathbb{K} \times \mathbb{Z} \times \mathbb{X} \times \mathbb{G} \times \mathbb{I} \times \mathbb{E} \times \mathbb{T}$ for working-age households and $\mathbb{S}=\mathbb{K} \times \mathbb{X} \times \mathbb{E} \times \mathbb{T}$ for retired households. Let $\mathbf{s} \in \mathbb{S}$, and denote by $\Gamma(\mathbf{s})$ the distribution of households over the state-space.

\subsection{Production sector}

There are two stand-in firms that act competitively. Their production functions are Cobb-Douglas, $A K^{\alpha} L^{1-\alpha}$, where $K$ and $L$ are aggregate capital and aggregate labor and $A$ is the total factor productivity. The first stand-in firm offers ESHI to its workers, but the second one does not. Under competitive behavior, the second firm pays each

\footnotetext{
${ }^{13}$ There is evidence that firms shift the costs of employer's contributions to health insurance to their workers. Gruber (1994) finds that wages of women of childbearing ages decreased after the maternity benefits become mandatory part of employer-based health insurance.

${ }^{14}$ The problem of a newly retired household is slightly different since he is still under insurance coverage from the previous period. Thus, $i_{t}$ is an additional state variable and out-of-pocket medical expenses are $x_{t}\left(1-q\left(x_{t}, i_{t}\right)\right)$.
} 
employee his marginal product of labor. Because capital is freely allocated between the two firms, the Cobb-Douglas production function implies that the capital-labor ratios of both firms are the same. Consequently, the factor prices are determined as follows:

$$
\begin{aligned}
& w=(1-\alpha) A K^{\alpha} L^{-\alpha}, \\
& r=\alpha A K^{\alpha-1} L^{1-\alpha}-\delta
\end{aligned}
$$

where $\delta$ is the depreciation rate.

The first firm must partially finance the health insurance premium for its employees. The cost is passed on to its employees through a wage reduction. The first firm subtracts an amount $c_{E}$ from the marginal product per effective labor unit. The zero profit condition implies

$$
c_{E}=\frac{\psi p\left(\int \mathbf{1}_{\left\{i_{H}^{\prime}(s)=G\right\}} \Gamma(s)\right)}{\int l_{t} z_{t}^{e, x} \mathbf{1}_{\left\{g_{t}=1\right\}} \Gamma(\boldsymbol{s})} .
$$

The numerator is the total contribution toward insurance premiums paid by the first firm. The denominator is the total effective labor working in the first firm.

\subsection{Insurance sector}

Health insurance companies in both private and group markets act competitively. The insurers can observe all state variables that determine the expected medical expenses of the individuals. ${ }^{15}$ Based on this assumption and the zero profit conditions, the insurance premiums can be written in the following way:

$$
p_{I}\left(x_{t}, t\right)=(1+r)^{-1} \gamma E M\left(x_{t}, t\right)+\pi
$$

for the non-group insurance market and

$$
p=(1+r)^{-1} \frac{\gamma\left(\int \mathbf{1}_{\left\{i_{H}^{\prime}(\mathbf{s})=G\right\}} E M\left(x_{t}, t\right) \Gamma(\boldsymbol{s})\right)}{\int \mathbf{1}_{\left\{i_{H}^{\prime}(\mathbf{s})=G\right\}} \Gamma(\boldsymbol{s})}
$$

for the group insurance market. Here, $E M\left(x_{t}, t\right)$ is the expected medical cost of an individual of age $t$ with current medical costs $x_{t}$ that will be covered by the insurance

\footnotetext{
${ }^{15}$ We assume that an insurance company in the individual market can observe all state variables relevant to the pricing of insurance, i.e., there is no asymmetric information. Before the ACA reform, in most states, insurance companies were allowed to do an underwriting when issuing an individual insurance policy. Moreover, individuals who got seriously ill shortly after obtaining a policy could be subject to ex-post underwriting that could result in their policy being retroactively canceled if it turned out that they had concealed some information about their health.
} 
company:

$$
E M\left(x_{t}, t\right)=\int x_{t+1} q\left(x_{t+1}, 2\right) \mathcal{G}\left(x_{t+1} \mid x_{t}, t\right) .
$$

$\gamma$ is a markup on prices due to the administrative costs in the individual and group markets; $\pi$ is the fixed costs of buying an individual policy. ${ }^{16}$ The premium in the nongroup insurance market is based on the discounted expected medical expenditure of an individual buyer. The premium for group insurance is based on a weighted average of the expected medical costs of those who buy group insurance.

\subsection{Government constraint}

The government runs a balanced budget, which implies

$$
\begin{gathered}
\int\left[\operatorname{Tax}(\boldsymbol{s})+\tau_{c} c_{t}(\boldsymbol{s})\right] \Gamma(\boldsymbol{s})-G= \\
\int_{t \geq R}\left[s s_{e}+q_{m e d} x_{t}-p_{m e d}\right] \Gamma(\boldsymbol{s})+\int T_{t}^{S I} \Gamma(\boldsymbol{s})+\int_{t<R} \mathbf{1}_{\left\{i_{H}^{\prime}=M\right\}} q\left(x_{t}, 1\right) x_{t} \Gamma(\boldsymbol{s})
\end{gathered}
$$

The left-hand side is the total tax revenue from all households net of the exogenous government expenditures $(G)$. The first term on the right-hand side is the net expenditures on Social Security and Medicare for retired households. The second term is the costs of guaranteeing the minimum consumption floor for households. The last term is the cost of Medicaid.

\section{Data and calibration}

The model is calibrated using nine waves of the Medical Expenditure Panel Survey (MEPS) dataset from 1999 to 2008. The MEPS links people into one household based on their eligibility for coverage under a typical family insurance plan. This Health Insurance Eligibility Unit (HIEU) defined in the MEPS dataset corresponds to our definition of a household. All statistics were computed for the head of the HIEU. The head is defined as the male with the highest income in the HIEU. If the HIEU does not have a male member, the female with the highest income is assigned as its head. All the statistics were computed using the longitudinal weights provided in the MEPS. Because each wave represents the population each year, the weight of each individual was divided by nine in the pooled sample.

The sample used for calibration includes all household heads who are at least 24 years old and have non-negative labor income (to be defined later). All level variables were

\footnotetext{
${ }^{16}$ Fixed costs capture the difference in overhead costs for individual and group policies, such as marketing and underwriting costs.
} 
converted into the price level of year 2002 (our base year) using the Consumer Price Index (CPI).

In the model, agents are born at the age of 25 and can live to a maximum age of 99. The model period is one year, so the maximum lifespan $N$ is 75 . Agents retire at the age of 65 , so $R$ is 41 . Tables 2 and 3 summarize the parametrization of the baseline model. The parameters in Table 2 were set outside the model, and the parameters in Table 3 were used to match some targets. We describe the calibration in more detail in Appendix A.

\begin{tabular}{|c|c|c|c|}
\hline \hline \multicolumn{3}{|c|}{ Parameters set outside the model } \\
\hline Parameter name & Notation & Value & Source \\
\hline Risk aversion & $\sigma$ & 5 & - \\
Consumption share & $\varkappa$ & 0.6 & French (2005) \\
Cobb-Douglas parameter & $\alpha$ & 0.33 & Capital share in output \\
Labor supply & $\bar{l}$ & 0.4 & - \\
Cutoff medical expenses & $\overline{x_{t}}$ & 90 th percentile & - \\
Consumption floor & $\underline{c}$ & $\$ 2,700$ & De Nardi et al. (2010) \\
Tax function parameters: & $a_{0}$ & 0.258 & Gouveia and Strauss (1994) \\
& $a_{1}$ & 0.768 & Gouveia and Strauss (1994) \\
Social Security replacement rates: & & & - \\
Below High-School & $s s_{1}$ & $40 \%$ & - \\
High-School \& College & $s s_{2}$ & $30 \%$ & Kahn et al. (2005) \\
Insurance loads & $\gamma$ & 1.11 & Data \\
Medicaid income threshold: & & & Data \\
Medicaid & $y^{\text {cat }}$ & $64 \%$ & Data \\
Medically Needy & $y^{\text {need }}$ & $53 \%$ & Total premiums $=2.11 \%$ of $Y$ \\
Asset test for Medically Needy & $k^{\text {pub }}$ & $\$ 2,000$ & Heathcote et al. (2010) \\
Medicare premium & $p^{\text {med }}$ & $\$ 1,055$ & Heathcote et al. (2010) \\
Productivity shock: & & & Erosa et al. (2011) \\
Persistence parameter & $\rho$ & 0.98 &
\end{tabular}

Table 2: Parameters of the model

\section{Baseline model performance}

Table 4 compares the aggregate health insurance statistics generated by the model with the ones observed in the data. The model was calibrated to match the ESHI take-up rates and individual insurance rates. ${ }^{17}$ However, the model also produces fractions of the uninsured and the publicly insured that are close to the data. The last four columns of Table 4 show insurance statistics by educational groups. The model does not target any of these statistics, but it still fares well along these dimensions. For each educational

\footnotetext{
${ }^{17}$ In this paper, we use the term "take-up rate" only in relation to the employer-based market, and it defines the fraction of people among those with an ESHI offer who choose to buy group insurance.
} 


\begin{tabular}{|c|c|c|c|}
\hline \multicolumn{4}{|c|}{ Parameters used to match some targets } \\
\hline Parameter name & Notation & Value & Source/Target \\
\hline Discount factor & $\beta$ & 0.992 & $\frac{K}{V}=3$ \\
\hline Depreciation rate & $\delta$ & 0.07 & $r=0.04$ \\
\hline Population growth & $\eta$ & $1.35 \%$ & $\%$ of people older than 65 \\
\hline Tax function parameter & $a_{2}$ & 0.652 & Balanced government budget \\
\hline Proportional tax & $\tau_{y}$ & $6.62 \%$ & Composition of tax revenue \\
\hline Fixed costs for insurance & $\pi$ & $\$ 22.7$ & $\%$ of individually insured \\
\hline Employer contribution & $\psi$ & $76.3 \%$ & ESHI take-up rate \\
\hline $\begin{array}{c}\text { Fixed costs of work } \\
\text { Healthy: }\end{array}$ & & & Employment profiles \\
\hline low education & $\phi_{1}(1)$ & 0.2800 & \\
\hline high education & $\phi_{1}(2)$ & 0.2650 & \\
\hline Unhealthy, low educ: & $\phi_{2}(t, 1)$ & & \\
\hline intercept & - & 0.0200 & \\
\hline slope & - & 0.0008 & \\
\hline Unhealthy, high educ: & $\phi_{2}(t, 2)$ & & \\
\hline intercept & - & 0.0450 & \\
\hline slope & - & 0.0025 & \\
\hline
\end{tabular}

Table 3: Parameters of the model

group, the model also closely tracks the employment and insurance profiles over the lifecycle for each health group (see Pashchenko and Porapakkarm (2013) for corresponding graphs).

\begin{tabular}{|c|cc|cc|cc|}
\hline \hline & \multicolumn{2}{|c|}{ All } & \multicolumn{2}{c|}{ Low education } & \multicolumn{2}{c|}{ High education } \\
\cline { 2 - 7 } & Data & Model & Data & Model & Data & Model \\
\hline Insured by ESHI (\%) & 63.0 & 64.4 & 33.3 & 29.1 & 68.5 & 70.6 \\
Individually insured (\%) & 7.6 & 7.3 & 5.5 & 3.8 & 8.0 & 8.0 \\
Uninsured (\%) & 20.2 & 19.7 & 39.5 & 43.2 & 16.6 & 15.6 \\
Publicly insured (\%) & 9.2 & 8.6 & 21.7 & 23.8 & 6.9 & 5.9 \\
ESHI take-up rate (\%) & 94.3 & 94.2 & 85.9 & 81.6 & 93.9 & 95.3 \\
Offer rate (\%) & 67.6 & 68.3 & 38.8 & 35.7 & 72.9 & 74.1 \\
Group premium/avg.income (\%) & 7.0 & 6.7 & - & - & - & - \\
\hline \hline
\end{tabular}

Table 4: Insurance statistics: data vs. model

\subsection{Price elasticity of demand for group health insurance}

In this paper, we study the possible consequences of the tax exclusion reform, so it is important that the model we use captures the price elasticity of demand for group health insurance. To compute price elasticity in the model, we consider how much the take-up 
rate changes in response to changes in the ESHI premium and then compute the implied elasticity. ${ }^{18}$ We find that the price elasticity in the model is non-linear, i.e., its magnitude depends on how much we change the ESHI premium compared with the baseline case. To make our elasticity comparable to micro estimates, we construct experiments in which we change the premium in the same way as in the studies we consider. More specifically, Chernew et al. (1997) simulate the change in the take-up rate in response to a $50 \%$ subsidy to the out-of-pocket ESHI premium, and their implied elasticity is -0.072. Based on the same change in the premium, the model produces an elasticity of $-0.11 .{ }^{19}$ Gruber and Washington (2005) estimate the sensitivity of the ESHI take-up rate to the share of after tax employee costs in total premiums. ${ }^{20}$ They consider the introduction of tax exclusions of employee's contributions for federal employees and find an elasticity equal to -0.02 . The policy episode they consider is equivalent to lowering the share of the employee contribution by approximately 10\%. Constructing an equivalent experiment, we find the elasticity of the take-up rate with respect to the after-tax share of employee premium to be equal to -0.08 . Overall, the elasticities produced by the model are broadly consistent with the micro estimates.

\section{Results}

This section is organized as follows. In Section 6.1, we illustrate the role of the existing tax subsidies in preventing the ESHI pool from unraveling. Next, in Section 6.2, we construct the following policy experiment: instead of the current tax exclusion, we introduce an individually-adjusted direct subsidy that only goes to individuals who will leave the pool if not subsidized. The subsidy scheme in this experiment is comparable with the simple example in Section 2. Our main goal in constructing this experiment is to understand how the ESHI take-up and total subsidy spending change compared with the baseline economy. In Section 6.3, we propose a reform of the current tax subsidy that aims to mimic the allocation of transfers, as in the case of the individually-adjusted direct subsidies. The effects of this tax subsidy reform after the implementation of the Affordable Care Act (ACA) are discussed in Section 6.4. Finally, we discuss the welfare effects of this tax reform in Section 6.5.

\footnotetext{
${ }^{18}$ The elasticity is equal to $100 \% * \frac{\Delta \text { Takeup }}{\text { Takeup }} / \frac{\Delta \text { Premium }}{\text { Premium }}$.

${ }^{19}$ In all our experiments, we consider a partial equilibrium environment, i.e., we do not allow the change in the composition of the ESHI pool to have feedback effects on premiums. We do this to be consistent with the way the micro studies we consider construct their elasticity.

${ }^{20}$ This share is defined as $\frac{\text { Employee's contribution }- \text { Tax savings }}{\text { Total premium }}$. Here, tax savings is the reduction in tax liability resulting from the tax exclusion of the ESHI premium.
} 


\subsection{The role of the tax exclusion in keeping the ESHI pool together}

To understand the role of the current tax subsidies in keeping the ESHI pool together we consider an experiment in which the ESHI premium is not excluded from taxable income. In this case, the total taxable income in equation (9) is determined in the following way:

$$
y_{t}^{N D}=r k_{t}+\widetilde{w} z_{t}^{e, x} l_{t}+\psi p \mathbf{1}_{\left\{i_{H}^{\prime}=G\right\}}-\max \left(0, x_{t}\left(1-q\left(x_{t}, i_{t}\right)\right)-0.075\left(\widetilde{w} z_{t}^{e, x} l_{t}+r k_{t}\right)\right)
$$

The total amount of tax is now determined as follows:

$T a x^{N D}=\mathcal{T}\left(y_{t}^{N D}\right)+\tau_{y} y_{t}^{N D}+\tau_{m e d}\left(\widetilde{w} z_{t}^{e, x} l_{t}+\psi p \mathbf{1}_{\left\{i_{H}^{\prime}=G\right\}}\right)+\tau_{s s} \min \left(\widetilde{w} z_{t}^{e, x} l_{t}+\psi p \mathbf{1}_{\left\{i_{H}^{\prime}=G\right\}}, \bar{y}_{s s}\right)$

Note that compared with equations (8) and (9), people who buy ESHI now must count both the employee's and employer's contributions as a part of their taxable income. For people who do not buy ESHI, the tax code remains the same.

\begin{tabular}{|l|c|c|c|c|c|}
\hline & \multicolumn{3}{|c|}{ ESI take-up $(\%)$} & Subsidy & Tax rate \\
\cline { 2 - 4 } & All & LE & HE & $(\%$ BS $)$ & $\tau_{y}(\%)$ \\
\hline Baseline & 94.2 & 81.6 & 95.3 & 100.0 & 6.86 \\
1. No tax subsidy & 6.3 & 4.0 & 6.5 & 0.0 & 6.07 \\
2. Differentiated subs. & 85.4 & 53.3 & 88.1 & 26.4 & 5.93 \\
3. Differentiated subs.+age-adjusted CR & 90.0 & 62.6 & 92.4 & 16.2 & 5.66 \\
\hline
\end{tabular}

Table 5: The effect of differentiated direct tax subsidy: the ESHI take-up rates and total spending on subsidies. LE (HE) denotes groups with low (high) education, BS denotes the baseline.

\begin{tabular}{|l|c|c|c|c|c|c|}
\hline & \multicolumn{3}{|c|}{ Employment (\%) } & \multicolumn{3}{|c|}{ Insurance (\%) } \\
\hline & All & LE & HE & Unins & Indiv & MCD \\
\hline Baseline & 89.7 & 75.6 & 92.2 & 19.7 & 7.3 & 8.6 \\
1. No tax subsidy & 86.9 & 74.7 & 89.2 & 62.4 & 22.7 & 10.8 \\
2. Differentiated subs. & 88.8 & 75.3 & 91.2 & 26.3 & 7.0 & 9.2 \\
3. Differentiated subs.+age-adjusted CR & 88.6 & 75.4 & 90.9 & 23.4 & 7.1 & 9.2 \\
\hline
\end{tabular}

Table 6: The effect of differentiated direct tax subsidy: employment and insurance. LE (HE) denotes groups with low (high) education, BS denotes the baseline.

The first row of Table 5 shows that the elimination of the tax exclusion results in the unraveling in the employer-based market: the take-up rate drops from $94.2 \%$ to $6.3 \%$. At the same time, the uninsured rate increases to $62.4 \%$ (Row 1 of Table 6 ). This suggests that tax subsidies are an important mechanism to maintain good risk-sharing in the employer-based pool. 
It is important to note that there is some evidence that the adverse selection pressure in community rated markets (especially with voluntary participation) is rather strong. The first piece of evidence comes from a policy episode in the early 1990s, when several states in the US introduced community rating regulations in the individual health insurance market. Clemens (2014) finds that these restrictions significantly decreased health insurance coverage and that this coverage decline escalated over several years, which is consistent with the adverse selection spiral scenario. Moreover, he finds that the market unraveling stopped once states with the community rating started expanding Medicaid. This happened because many unhealthy individuals switched from private to public insurance, resulting in better average health among the remaining participants of the individual market. The second piece of evidence comes from episodes of the adverse selection against a specific health insurance plan in the employer-based market. The notable case of the complete unraveling happened in the mid-1990s at Harvard University (for a full description see Cutler and Zeckhauser, 1998). Harvard offered two insurance plans that significantly differed in their generosity but initially cost almost the same to employees. In the mid-1990s the premiums of the two plans diverged, which triggered the adverse selection spiral: more healthy people were choosing the cheaper but less generous plan, resulting in worse risk composition among those purchasing the more generous plan, which increased its premium. This trend reinforced itself every year and eventually the generous plan was disbanded.

It is important to compare out results in Table 5 with Jeske in Kitao (2009), who also study the effects of the removal of the tax subsidy in the employer-based market. They find that the elimination of the tax exclusion results in a less dramatic unraveling of the ESHI market: the take-up rate in their case decreases by approximately $36 \%$. The key difference between our modeling approach and Jeske and Kitao (2009) is that we construct a full life-cycle model. In contrast, Jeske and Kitao (2009) use a stochastic aging framework: individuals can be either young or old. Only young individuals can work and participate in the employer-based pool, whereas all old individuals are retired and covered by Medicare. This way, the only difference in the risk of participants in the ESHI pool is due to health. In our setup, participants in the ESHI pool differ not only by health but also by age. The average medical spending increases quickly with age, meaning that cross-subsidization between the young and the old is substantial. Our simple model in Section 2 shows that the more heterogeneous the pool is, the harder it is to keep it together. Because having people of different ages in the ESHI pool makes this pool much more heterogeneous, the removal of the tax subsidy results in a larger exit from the pool and thus a stronger adverse selection spiral.

To provide the intuition behind our result of the unraveling of the ESHI market, Figure (5) compares the risk-adjusted premiums in the individual market with the out- 
of-pocket costs of ESHI in the baseline economy. The out-of-pocket costs of ESHI ( $p^{O O P}$ ) are defined in the following way:

$$
p^{O O P}=p(1-\psi)+\Delta T a x
$$

where $p(1-\psi)$ is the employee's contribution and $\Delta$ Tax is the difference in tax payments resulting from the purchase of ESHI, $\Delta$ Tax $=\operatorname{Tax}^{i_{H}^{\prime}=G}-\operatorname{Tax}_{i_{H}^{\prime} \neq G}$. If the ESHI premium is excluded from the taxable income, an individual can save on taxes by buying employerbased insurance, i.e., $\Delta \operatorname{Tax}<0$. If the tax exclusion is removed, an individual buying ESHI must pay additional taxes because the employer's contributions are now counted as taxable income, i.e., $\Delta \operatorname{Tax}>0$.

The difference between the out-of-pocket ESHI costs with and without the tax exclusion is large enough to trigger the adverse selection spiral. As shown in Figure (5), for young people in the two lowest medical expenses grids (i.e., with medical expenses less than the 60th percentile), the out-of-pocket costs of ESHI exceed their risk-adjusted prices in the individual market after the tax subsidy is removed. ${ }^{21}$ These people initiate the unraveling by dropping out of the employer-based market, which leads to an increase in the ESHI premium and a further unraveling of the pool.

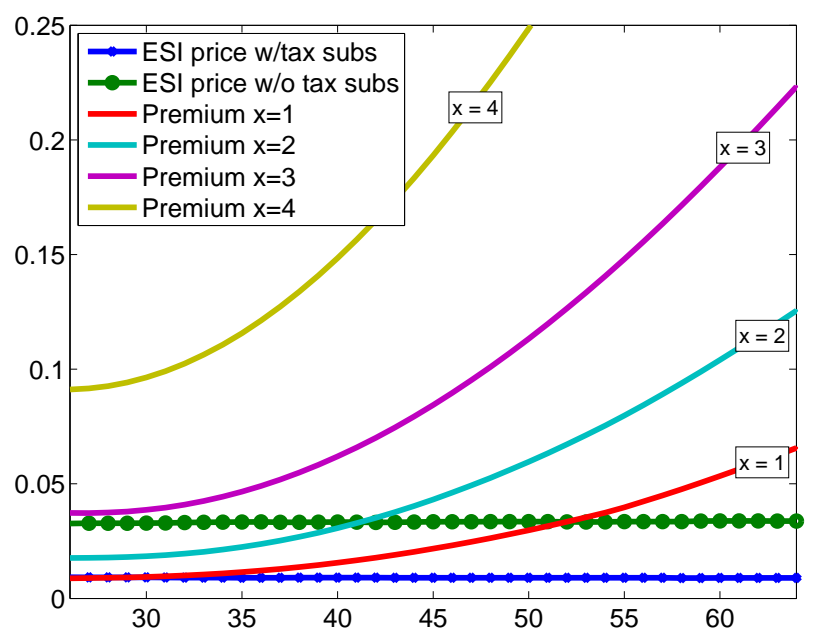

Figure 5: Individual premiums for people in different medical expense grids vs. average out-of-pocket costs of ESHI with and without tax exclusion. Premiums are normalized by the average GDP per capita.

Another observation from Figure (5) is that for older people and people in the high medical costs grids $\left(x_{t}=3,4,5\right)$, the out-of-pocket costs of ESHI are substantially lower than their risk-adjusted individual premiums even when the tax exclusion is removed. These people enjoy large implicit cross-subsidies from people with low expected medical costs and have incentives to buy ESHI even without tax subsidies. Figure (6) illustrates

\footnotetext{
${ }^{21}$ When constructing Figure (5), the premium used to compute $p^{O O P}$ after removing the tax exclusion is fixed as in the baseline. After the unraveling starts, this price will substantially increase.
} 
this point further by showing the markup that individuals with different expected medical costs face in the ESHI pool. The markup is measured as a percentage difference between the risk-adjusted price in the individual market and the out-of-pocket costs of ESI. ${ }^{22}$ The negative markup means that an individual is overpaying compared with his risk-adjusted price, thus cross-subsidizing other participants in the pool, whereas the positive markup means that an individual is cross-subsidized. The solid lines in Figure (6) show that the community rating imposes a large burden on healthy people younger than 35 years old - their markup can be as high as -250\%. In contrast, people over the age of 60 with bad health enjoy a discount of approximately $90 \%$ of their risk-adjusted price when they participate in the group market. We will explore the possibilities of designing subsidies that take this cross-subsidization into account in the next section.
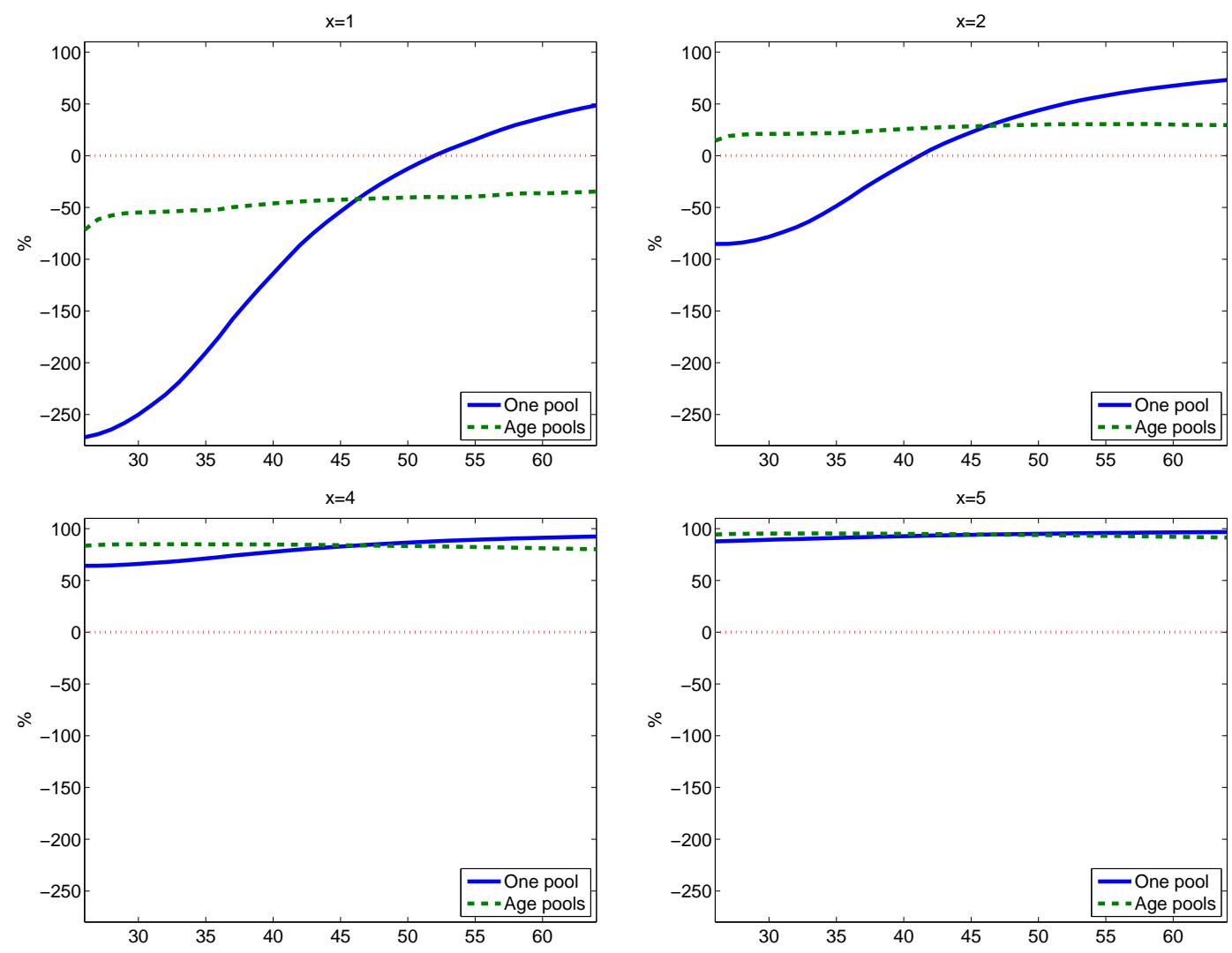

Figure 6: Markup for people in different medical expense grids in the ESHI market. The solid lines are the markup in a single pool in the baseline economy. The dashed lines are the markup in case when ESHI premiums are age-adjusted.

Another important observation from Tables 5 and 6 is that elimination of the tax subsidy leads to a significant decrease in employment: the percentage of the working population decreases from $89.7 \%$ in the baseline economy to $86.9 \%$ in the economy without the tax subsidy. This happens because in the economy without the tax subsidy, the

\footnotetext{
${ }^{22}$ More specifically, the markup is computed as $100 \% * \frac{p_{I}\left(x_{t}, t\right)-p^{O O P}}{p_{I}\left(x_{t}, t\right)}$
} 
employer-based market unravels. ESHI is an important part of compensation for many people, and its elimination decreases their incentives to work. Feng and Zhao (2014) explore the interaction between the labor supply and ESHI in detail and find that this insurance provides an important incentive to work. French and Jones (2011) show that employer-based health insurance has significant effect on retirement decisions. ${ }^{23}$

\subsection{The effects of direct differentiated subsidies}

In this section, we consider an alternative subsidy scheme that only targets people with weak incentives to participate in the ESHI pool. More specifically, we remove the tax exclusion of the ESHI premium and introduce a direct differentiated subsidy instead. This subsidy compensates people with low expected medical costs more because in the pool, they cross-subsidize people with high expected medical costs. The subsidy is determined in the following way:

$$
\operatorname{subs}_{i}=\max \left\{0, p^{O O P}-\frac{E M\left(x_{t}, t\right)}{1+r}\right\} .
$$

An individual with a positive subsidy receives a difference between his actuarially fair price $\frac{E M\left(x_{t}, t\right)}{1+r}$ and his out-of-pocket costs of ESHI, $p^{O O P}$. Note that only individuals who are likely to leave the pool if they are not subsidized receive a positive subsidy.

The results of the implementation of this subsidy scheme are presented in the second row of Table 5. The differentiation of the subsidy results in a small decrease in the take-up rate: from $94.2 \%$ to $85.4 \% .{ }^{24}$ At the same time, the total spending on these direct subsidies represents only $26.4 \%$ of the tax expenditures used to keep the ESHI pool together in the baseline economy. ${ }^{25}$ In other words, removing the subsidy from those who have already been cross-subsidized in the pool results in almost the same level of risk-sharing at one-fourth of the costs.

The left panel of Figure (7) illustrates how the size of the subsidy varies by age and health. Not surprisingly, people who receive the highest subsidies are those younger than

\footnotetext{
${ }^{23}$ It is important to point out that the negative effect of the elimination of ESHI on labor supply happens despite the fact that the costs of employer's contributions are fully shifted back to employees. This is because for some individuals (especially old and unhealthy), health insurance is worth more than the offset in their wage. Elimination of employer-based insurance decreases their incentives to work despite the increase in earnings because the total value of their compensation decreases.

${ }^{24}$ Note that not all individuals are willing to buy health insurance, even at actuarially fair prices. This happens because health insurance covers only part of the medical costs. At the same time, uninsured individuals can rely on government means-tested transfers provided through the consumption minimum floor. Pashchenko and Porapakkarm (2015a) illustrate the effect of the consumption floor on the insurance demand in more detail.

${ }^{25}$ In the baseline economy, the costs to keep the pool together represent the tax revenue forgone because of the tax exclusion. It is computed as follows: $\int\left[\operatorname{Tax}^{N D}(\boldsymbol{s})-\operatorname{Tax}(\boldsymbol{s})\right] \Gamma(\boldsymbol{s})$. In the economy with the differentiated subsidy scheme, these costs are the direct subsidy spending.
} 
35 years old and in the lowest medical cost grid (with medical expenses in the bottom 30th percentile of the distribution for each age). These people have the lowest expected medical expenses and are the most disadvantageous group in the employer-based pool (see the left panel of Figure (6)); therefore, they should receive the highest compensation. It is important to note that people over age 55 and those in medical cost grids 4 and 5 (with medical expenses in the top 10 percent of the distribution for each age) never get subsidized, yet they still remain in the pool. This suggests the inefficiency of uniform subsidization.
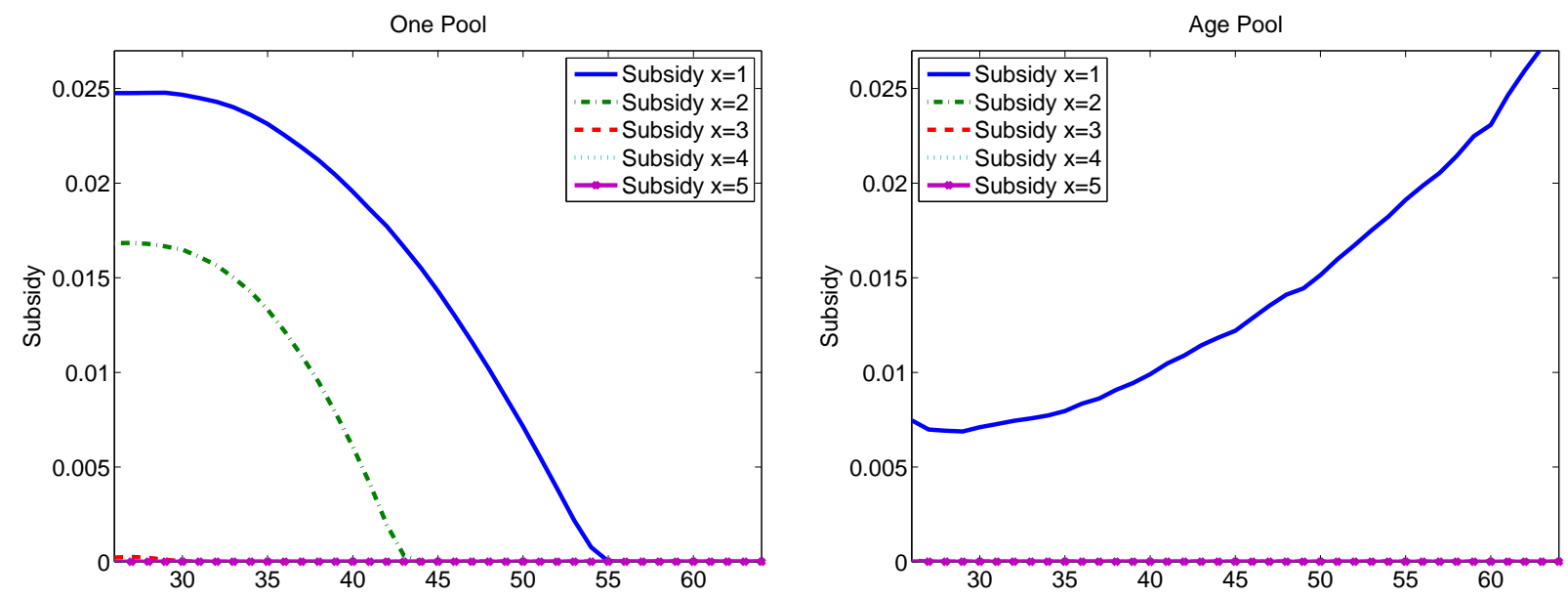

Figure 7: Differentiated subsidies in the case of one pool (left panel) and age pool (right panel). On the left panel, the lines for medical cost grids 3, 4, and 5 lie on the horizontal axis. On the right panel, the lines for medical cost grids 2, 3, 4, and 5 lie on the horizon axis. Subsidies are normalized by the average GDP per capita.

The left panel of Figure (7) illustrates that young healthy people are the most "costly" participants in the community-rated pool because they have to be highly subsidized to stay in the pool. This happens because all people face the same premium in the uniform community rating. Because the expected medical costs increase steeply with age, this implies a large cross-subsidization from the young to the old. The whole system of transfers inside this pool can be summarized as follows: the young cross-subsidize the old, and the government directly subsidizes the young so they will stay in the pool. In contrast, if the community rating in the ESHI market is age-adjusted, there will be no cross-subsidization from the young to the old but only from the healthy to the unhealthy. Because the difference in expected medical costs between healthy and unhealthy individuals of the same age is smaller than this difference between the healthy young and the unhealthy old, age-adjusted pools imply less cross-subsidization; thus, less direct subsidies are needed to maintain a high participation rate in the pool.

In the next experiment, we consider the above differentiated subsidy scheme when we introduce an age-adjusted community rating in the group market, i.e., we allow the 
ESHI premium to depend on age (but not on the current medical costs) of an individual. Thus, the ESHI premium in Equation (16) is replaced by an age-dependent premium, as indicated below:

$$
p(\hat{t})=(1+r)^{-1} \gamma \frac{\left(\int_{\mathbf{t}=\widehat{t}} \mathbf{1}_{\left\{i_{H}^{\prime}(\mathbf{s})=G\right\}} E M\left(x_{t}, t\right) \Gamma(\boldsymbol{s})\right)}{\int_{\mathbf{t}=\widehat{t}} \mathbf{1}_{\left\{i_{H}^{\prime}(\mathbf{s})=G\right\}} \Gamma(\boldsymbol{s})} .
$$

The third row in Table 5 shows that the implementation of the differentiated subsidy scheme together with the age-adjusting community rating results in a take-up rate equal to $90.0 \%$ (compared with $94.2 \%$ in the baseline). Importantly, the total spending on subsidies now represents only $16.2 \%$ of the tax expenditures in the baseline economy. In other words, when cross-subsidization along the dimension of age is removed, it is much cheaper to maintain good risk-sharing in the employer-based market. The dashed lines in Figure (6) show that the markup young people face under the age-adjusted community rating is much lower than that under the uniform community rating. As the right panel of Figure (7) illustrates, now only people in the lowest medical cost grid (those with medical expenses in the bottom 30 th percentile for each age) can receive a direct subsidy. The amount of this subsidy increases with age because the expected medical expenses of people in the first medical cost grid increase much more slowly with age than the average medical expenses. As they age, people who stay in the lowest medical cost grid need higher compensation to agree to pool their risks with people in higher medical cost grids.

\subsection{Reforming the current tax exclusion of ESHI premiums}

The previous section illustrates that we can use direct differentiated subsidies to maintain good risk-sharing in the employer-based pool at relatively low costs. In this section, we investigate whether the current tax subsidy can be modified to achieve a similar outcome. Tax exclusion is a less flexible instrument than direct subsidy. However, one result from the previous section that can still be applied is that only people with weak incentives to participate in the ESHI pool should be subsidized. To mimic this result, we consider a tax subsidy reform that targets only people who receive the direct subsidy in the experiment described in Section 6.2. At the same time, we remove the tax exclusion from people who do not receive any direct subsidy. ${ }^{26}$

The left panel of Figure (7) illustrates that in the direct differentiated subsidy scheme, two groups are subsidized: people in the lowest medical expense grid (with medical expenses in the bottom 30th percentile for each age) and younger than 55 years old, and

\footnotetext{
${ }^{26}$ In this experiment, the taxable income and tax payments are determined according to Equations (8) and (9) for the ESHI participants that are allowed to keep the tax exclusion, and according to equations (18) and (19) for the rest of the ESHI participants.
} 


\begin{tabular}{|l|c|c|c|c|c|}
\hline & \multicolumn{3}{|c|}{ ESI take-up $(\%)$} & Subsidy & Tax rate \\
\cline { 2 - 5 } & All & LE & HE & BS $)$ & $\tau_{y}(\%)$ \\
\hline Baseline (pre-ACA economy) & 94.2 & 81.6 & 95.3 & 100.0 & 6.86 \\
1. No tax subsidy & 6.3 & 4.0 & 6.5 & 0.0 & 6.07 \\
Tax subsidy only to a certain group: & & & & & \\
2. $\left(x_{t}=1\right.$ and age $\left.\leq 55\right)$ or $\left(x_{t}=2\right.$ and age $\left.\leq 43\right)$ & 92.5 & 70.8 & 94.3 & 43.9 & 6.15 \\
3. $x_{t}=1+$ age-adj CR & 97.1 & 81.3 & 98.5 & 34.6 & 5.89 \\
\hline
\end{tabular}

Table 7: The effects of tax subsidy reforms. LE (HE) denotes groups with low (high) education, BS denotes the baseline.

people in the second lowest medical expense grid (with medical expense above the 30th percentile but below the 60 th percentile) and younger than 43 years old. To imitate these results, we consider a policy under which only these two groups are allowed to keep the tax exclusion. The second row of Table 7 illustrates the effect of this reform (Table 10 in Appendix B shows the effect on the employment and insurance status). Allowing young and healthy people to keep the tax exclusion prevents the ESHI pool from unraveling: the take-up rate is $92.5 \%$, which is only $2 \%$ lower than in the baseline. At the same time, the costs of the tax subsidy go down more than twofold compared with the baseline level $(43.9 \%){ }^{27}$ Note that even though these savings are considerable, they are not as high as in the case of direct differentiated subsidies. This happens because the size of the tax subsidy (unlike the size of the direct subsidy) cannot be adjusted for individual risks. The left panel of Figure (7) shows that the size of the direct subsidy decreases steeply with age, and this represents a significant source of savings because older people need less incentives to join the pool.

The results in Section 6.2 demonstrate that a high participation rate in the ESHI pool can be achieved at significantly lower costs if the community rating in the ESHI market is age-adjusted. In the next experiment, we introduce age-adjusted premiums in the ESHI market. At the same time, we allow only people in the lowest medical expense grid (with medical expense in the bottom 30th percentile) to keep the tax exclusion because only this group receives direct subsidies in this case, as shown in the right panel of Figure (7). Row 3 of Table 7 shows that this reform results in the take-up rate being slightly higher than the baseline level (97.1\%). At the same time, the costs of these tax subsidies represent only one-third $(34.6 \%)$ of the baseline level.

\footnotetext{
${ }^{27}$ In each experiment considered in Tables 7 and 8, we evaluate the total subsidy spending (or forgone tax revenue) from $\int\left[\operatorname{Tax}^{N D}(s)-\operatorname{Tax}(s)\right] \Gamma(s)$, where the tax parameters are the equilibrium tax rate in that economy. Note that for individuals who are not allowed to keep the tax exclusion, $\operatorname{Tax} x^{N D}=\operatorname{Tax}$
} 


\subsection{Elimination of the tax exclusion after the ACA}

This section considers the effects of our proposed tax exclusion reform after the implementation of the ACA. The main changes that the ACA introduces to the economy are as follows. First, there will be an age-adjusted community rating in the individual market, meaning that premiums can depend only on age but not on the health conditions of individuals. Second, low-income individuals will receive subsidies to buy health insurance in the individual market. The subsidy will be determined based on a sliding scale. People with income below $133 \%$ of the Federal Poverty Line (FPL) will receive the highest subsidy, but people with income above $400 \%$ of FPL will not receive any subsidy. Third, the income eligibility threshold for the general Medicaid program $\left(y^{\text {cat }}\right)$ will increase to $133 \%$ of FPL. Fourth, people who remain uninsured will have to pay penalties. Appendix $\mathrm{C}$ details how the ACA changes our baseline model. ${ }^{28}$

\begin{tabular}{|l|c|c|c|c|c|}
\hline \multirow{2}{*}{} & \multicolumn{3}{|c|}{ ESI take-up (\%) } & Subsidy & Tax rate \\
\cline { 2 - 4 } & All & LE & HE & $(\%$ BS $)$ & $\tau_{y}(\%)$ \\
\hline Post-ACA economy & 94.2 & 75.6 & 95.9 & 100.0 & 6.86 \\
1. No tax subsidy & 52.6 & 31.6 & 54.4 & 0.0 & 5.70 \\
2. No tax subsidy, no penalties & 5.3 & 3.8 & 5.4 & 0.0 & 6.44 \\
Tax subsidy only to a certain group: & & & & & \\
3. $\left(x_{t}=1\right.$ and age $\left.\leq 55\right)$ or $\left(x_{t}=2\right.$ and age $\left.\leq 43\right)$ & 93.6 & 72.5 & 95.5 & 47.0 & 6.32 \\
4. $x_{t}=1+$ age-adjusted CR & 94.4 & 74.3 & 96.2 & 35.8 & 6.22 \\
\hline
\end{tabular}

Table 8: The effects of the partial removal of the tax exclusion after the ACA. LE (HE) denotes groups with low (high) education. Here, BS denotes the baseline for the post-ACA economy.

The first row of Table 8 reports the ESHI take-up rate for the long-run equilibrium after the implementation of the ACA. Table 11 in Appendix B reports the employment and insurance statistics. We will use this economy as a reference when comparing the effect of the tax subsidy reforms after the ACA is implemented. When implementing the ACA, we assume that all additional government spending needed to pay for subsidies and expanding Medicaid are financed by increasing the progressive income tax. This increase disproportionably falls on high-income people to reflect that an important source of the ACA financing comes from levying higher taxes on the rich. More specifically, we adjust the parameter $a_{0}$ of the tax function to balance the government budget during the implementation of the ACA. As a result, this parameter increases from 0.258 (baseline level) to 0.285 . The resulting average tax rate for a person with average income increases

\footnotetext{
${ }^{28}$ In our modeling of the post-ACA economy, we abstract from two provisions of this reform: the limit on the age-adjustment of premiums in the individual market and the employer mandate. We abstract from the former provision because there can be multiple equilibriums in the age-adjusted community rated individual market with limits on the age-adjustment. We abstract from the employer mandate because it only applies to large firms (more than 50 employees), and in the pre-ACA economy, most of large firms already offer group insurance (96\%).
} 
by 1.2 percentage points. ${ }^{29}$

Row 1 of Table 8 shows the effects of the complete elimination of the tax exclusion after the reform (Table 11 in Appendix B reports the corresponding changes in employment and insurance). In contrast to the economy before the ACA, removing the tax subsidies does not lead to the full unraveling of the employer-based pool: the take-up rate only decreases to $52.6 \%$. Row 2 of Table 8 shows that this high take-up rate is due to the penalty for being uninsured: if the penalty is removed, the elimination of the tax subsidy brings the take-up rate down to $5.3 \%$.

Row 3 of Table 8 shows the effects of the reform that allows only two groups to keep the tax exclusion: people in the lowest medical expense grid (with medical expenses in the bottom 30th percentile) who are younger than 55 years old, and people in the second lowest medical expense grid (with expenses between the 30th and 60th percentiles) who are younger than 43 years old. This tax subsidy reform results in a slightly lower take-up rate $(93.6 \%$ compared with $94.2 \%$ ), but the tax expenditures constitute less than half $(47 \%)$ of the post-ACA baseline level.

Row 4 of Table 8 shows the results of targeting the tax exclusion only at people in the lowest grid of medical expenses combined with age-adjustment of premiums in the ESHI market. As before, this policy achieves good risk-pooling with the lowest costs: the take-up rate is the same as in the post-ACA baseline (around 94\%), and the tax expenditures constitute $35.8 \%$ of the post-ACA baseline level.

\subsection{Welfare effects}

The important finding from Sections 6.3 and 6.4 is that the reform that achieves good risk-sharing in the ESHI market at the lowest costs involves two steps: i) the existing tax subsidy should be targeted only at low-risk people, and ii) ESHI premiums should be age-adjusted. This section evaluates the welfare effects of this tax subsidy reform and compares them with those when the tax exclusion is completely eliminated. Rows 1 and 4 of Table 9 show that the complete elimination of the tax subsidy results in substantial ex-ante welfare losses, both in the pre-ACA and post-ACA economies: the consumption equivalent variations (CEV) are equal to $-0.46 \%$ and $-0.36 \%$ of the annual consumption, respectively. ${ }^{30}$ There is heterogeneity in welfare effects by educational group: people with high education lose approximately $1 \%$ of their annual consumption, whereas people with

\footnotetext{
${ }^{29}$ For a full analysis of the effects of the ACA on the economy, see Pashchenko and Porapakkarm (2013).

${ }^{30}$ Let $V^{B}$ and $V^{E}$ denote the value function of a newborn in the baseline economy and the experimental economy, respectively. The CEV can be defined as:
}

$$
C E V=100 *\left[1-\left(\frac{V^{B}}{V^{E}}\right)^{\frac{1}{\chi(1-\sigma)}}\right]
$$


low education gain. Many people in the latter group do not have access to the employerbased market, so they do not suffer from its unraveling. Instead, they can enjoy a lower tax rate due to lower government tax expenditures.

\begin{tabular}{|l|c|c|c|c|c|c|}
\hline & \multicolumn{2}{|c|}{ CEV (\%) } & Subsidy & Tax rate & ESHI \\
& All & LE & HE & $(\%)$ & $\tau_{y}(\%)$ & Take-up \\
\hline Before ACA & & & & & & \\
Pre-ACA baseline & - & - & - & 100.0 & 6.86 & 94.2 \\
1. No tax subsidy & -0.46 & 0.27 & -1.08 & 0.0 & 6.07 & 6.03 \\
Tax subsidy only to a certain group: & & & & & & \\
2. $x_{t}=1+$ age-adj CR & 0.18 & 0.41 & -0.01 & 34.6 & 5.89 & 97.1 \\
3. $x_{t}=1$ and income $<2$ FPL+age-adj CR & 0.61 & 0.79 & 0.46 & 42.4 & 5.89 & 98.5 \\
\hline After ACA & & & & & & \\
Post-ACA baseline & - & - & - & 100.0 & 6.86 & 94.2 \\
4. No tax subsidy & -0.36 & 0.41 & -0.98 & 0.0 & 5.70 & 52.6 \\
Tax subsidy only to a certain group: & & & & & & \\
5. $x_{t}=1+$ age-adj CR & -0.15 & 0.16 & -0.40 & 35.8 & 6.22 & 94.4 \\
6. $x_{t}=1$ and income $<2 *$ FPL+age-adj CR & 0.13 & 0.42 & -0.11 & 42.0 & 6.23 & 94.7 \\
\hline
\end{tabular}

Table 9: Ex-ante welfare of newborns for different policy experiments

Rows 2 and 5 of Table 9 show the welfare effects of the tax reform that combines the age-adjusted community rating in the ESHI market with the removal of the tax exclusion from all people except those in the bottom $30 \%$ of the medical spending distribution for each age. Before the ACA, this tax subsidy reform brings positive welfare gains $(0.18 \%)$, but after the ACA, the welfare effects become negative (-0.15\%). In general, this policy withdraws subsidies from all people whose medical expenses are not in the bottom $30 \%$ of the medical expense distribution, regardless of their income. However, even though the average income of the ESHI pool participants is relatively high, there is substantial income heterogeneity. The loss of tax subsidies by low-income individuals with high medical costs negatively affects welfare. At the same time, the introduction of age-adjusted premiums in the ESHI market positively affects welfare because it results in a decrease in ESHI premiums for young people, many of whom have low income. ${ }^{31}$ Before the implementation of the ACA, the positive welfare effect from age-adjusted ESHI premiums offsets the negative welfare effect from withdrawing tax subsidies from low-income individuals. In contrast, after the ACA, the opposite is true because the tax rate is higher; thus, the size of the tax subsidy is higher as well. Withdrawing this subsidy from the low-income group yields a more noticeable welfare effect that cannot be fully offset by the age-adjustment of premiums in the group market.

The resulting number represents the percentage of the annual consumption a newborn in the experimental economy is willing to give up to be indifferent between the baseline and experimental economies. The positive number implies welfare gains.

${ }^{31}$ The introduction of the age-adjusted community rating in the ESHI market in the baseline economy results in ex-ante welfare gains equivalent to $0.27 \%$ of the annual consumption. 
To improve the welfare outcomes, we extend the tax subsidy to people with income below $200 \%$ of FPL. Rows 3 and 6 of Table 9 show the welfare effects of this modified policy before and after the ACA. Before the ACA, the resulting welfare gains increase to $0.61 \%$, and after the ACA, to $0.13 \%$. However, tax expenditures do not increase much: before the ACA, the tax expenditures increase from $34.6 \%$ to $42.4 \%$ of the baseline level, and after the ACA, from $35.8 \%$ to $42.0 \%$ of the level of the post-ACA baseline. In other words, both before and after the ACA, the spending on tax subsidies can be decreased by almost $60 \%$ without unraveling of the employer-based market and without reducing the welfare. To achieve these results, it is important i) to target tax subsidies at people with low expected medical expenses and people with low income, and ii) to allow for age-adjusted premiums in the group market.

\subsection{Implementation}

The essence of our policy proposal is that instead of subsidizing all people buying employer-based insurance the tax subsidy should be targeted only at a group of relatively healthy people. With regard to the implementation of this policy, the question is how to identify the group of people who should receive the tax subsidy. Our suggestion is to subsidize people whose current medical expenses are close to zero. ${ }^{32}$ This approach should result in very low administrative costs. The ACA requires each individual to obtain health insurance or pay a penalty. Individuals with insurance must obtain a certificate from their insurance company confirming that they are insured. For those individuals who want to receive the tax subsidy, the certificate proving that they are insured can be combined with a statement of their medical expenses in the current period. ${ }^{33,34}$

In general, it is possible to use additional criteria to target people whose presence in the pool is important to keep the premium low. For example, health insurance companies providing employer-based insurance accumulate information on the usage of health care for participating employees. This information can also be used to determine eligibility for tax subsidies. What we show in this paper is that the total amount of unnecessary

\footnotetext{
${ }^{32}$ More specifically, we suggest targeting subsidies at people whose medical expenses are below the 30 th percentile of the medical expense distribution of their age. Figure (8) in the Appendix shows that people in this group have almost zero medical spending over most of their life-cycle.

${ }^{33}$ In our model, the evolution of health is exogenous and cannot be affected by the behavior of individuals or by investments in health. In this environment, the tax subsidy for employer-based insurance is a tool to keep the risk pool together and to avoid the adverse selection spiral. Modeling the endogenous evolution of health is beyond the scope of this paper for computational reasons. However, it is important to note that in such an environment, a subsidy that is negatively linked to medical spending may have an additional positive role of promoting healthy behavior.

${ }^{34}$ It is important to note that in our model, medical spending is exogenous, so we abstract from the potential role of these types of subsidies on decreasing moral hazard in medical consumption. Pashchenko and Porapakkarm (2015b) explore the role of moral hazard in medical consumption and discuss possible ways to decrease it.
} 
subsidization is quite large and that even targeting subsidies based on a rather rough risk classification can achieve non-trivial tax savings. ${ }^{35}$

\section{Conclusion}

In this paper, we explore the possible reform of the current tax subsidy scheme for people who buy employer-based health insurance. We show that even though the complete elimination of tax subsidies leads to the unraveling of the employer-based market, there is room for substantial savings on the tax expenditure by targeting tax subsidies. We show that good risk-pooling in the employer-based market can be achieved at much lower costs if the tax code takes into account that people have different incentives to participate in the employer-based pool. In the employer-based market, high-risk people receive implicit cross-subsidies from low-risk people and are willing to join the pool even without any subsidies. In contrast, for low-risk people, the employer-based insurance pool is less attractive. By building on this intuition, we propose a tax subsidy reform that can maintain the same level of risk-pooling in the group market as in the baseline economy but at one-third of the costs. To achieve these results, only people in the bottom $30 \%$ of medical expenses distribution should be allowed to keep the tax exclusion. In addition, the premiums in the group market should be age-adjusted to remove cross-subsidies from the young to the old and to make the ESHI pool more attractive for the young. To improve the welfare outcome of this reform, it is important to extend tax exclusion to people with income below $200 \%$ of FPL, which results in the tax expenditure being equal to around $40 \%$ of the baseline level.

\footnotetext{
${ }^{35}$ The suggested subsidy results in an insurance pricing scheme similar to the one used in car insurance. An insurance company usually reduces the premiums for drivers who do not have accidents in the previous year.
} 


\section{References}

[1] Aizawa, N., Fang, H., 2012. Equilibrium Labor Market Search and Health Insurance Reform. Mimeo, University of Pennsylvania.

[2] Attanasio, O., Kitao, S., Violante G., 2011. Financing Medicare: A General Equilibrium Analysis. In Shoven, J.B. (Ed.), Demography and the Economy, University of Chicago Press.

[3] Capatina, E., 2014. Life-cycle Effects of Health Risk. Journal of Monetary Economics

[4] Congressional Budget Office, 2015. The 2015 Long-Term Budget Outlook. Available at https://www.cbo.gov/sites/default/files/114th-congress-20152016/reports/50250-LongTermBudgetOutlook-4.pdf

[5] Chernew, M., Frick, K. McLaughlin, C., 1997. The Demand for Health Insurance Coverage by Low-Income Workers: Can Reduced Premiums Achieve Full Coverage? Health Services Research, 32 (4): 453-470.

[6] Clemens, J., 2012. "Regulatory Redistribution in the Market for Health Insurance". NBER Working paper 19904.

[7] Cutler, D., and Zeckhauser, R., 1998. Adverse Selection in Health Insurance. In Frontiers in Health Policy Research, Volume 1, Alan Garber, 1-31. Cambridge: Mit Press.

[8] De Nardi, M., French, E., Jones, J., 2010. Why Do the Elderly Save? Journal of Political Economy, 118(1), 39-75.

[9] Erosa, A., Fuster, L., Kambourov, G. 2011 Towards a micro-founded theory of aggregate labor supply. IMDEA Working Papers N 2011-13.

[10] Feng, Z., Zhao, K., 2014. Employment-based Health Insurance, Uncertain Medical Expenses, and Aggregate Labor Supply. Mimeo, University of Connecticut.

[11] Floden, M., 2008. A Note on the Accuracy of Markov-chain Approximations to Highly Persistent AR(1) Processes. Economic Letters 99(3), 516-520.

[12] French, E., 2005. The Effects of Health, Wealth, and Wages on Labor Supply and Retirement Behaviour. Review of Economic Studies, 72(2), 395-427.

[13] Gouveia, M., Strauss, R., 1994. Effective Federal Individual Income Tax Functions: An Exploratory Empirical Analysis. National Tax Journal, 47(2), 317-339. 
[14] Gruber, J., 1994. "The Incidence of Mandated Maternity Benefits". American Economic Review, Vol. 84, No. 3, pp. 622-641

[15] Gruber, J., 2011. The Tax Exclusion for Employer-Sponsored Health Insurance. National Tax Journal, 64 (2), 511-530.

[16] Gruber, J., and Washington, E., 2005. Subsidies to Employee Health Insurance Premiums and the Health Insurance Market. Journal of Health Economics, 24: 253276.

[17] Hai, R., 2012. The Determinants of Rising Inequality in Health Insurance and Wages: An Equilibrium Model of Workers' Compensation and Health Care Policies. Mimeo, University of Pennsylvania.

[18] Hansen, G., Hsu, M., Lee, J., 2014. Health Insurance Reform: The impact of a Medicare Buy-In. Journal of Economic Dynamics and Control, 45, 315-329.

[19] Heathcote, J., Storesletten, K., Violante, G. 2010 The Macroeconomic Implications of Rising Wage Inequality in the United States. Journal of Political Economy, 118(4), 681-722.

[20] Hsu, M., 2013. Health Insurance and Precautionary Saving: A Structural Analysis. Review of Economic Dynamics, 16:3, 511-526.

[21] Hubbard, G., Skinner, J., Zeldes, S., 1994. The Importance of Precautionary Motives in Explaining Individual and Aggregate Saving. Carnegie-Rochester Conference Series on Public Policy 40(1), 59-125.

[22] Hugget, R., 1993. The Risk-free Rate in Heterogeneous-Agent Incomplete-insurance Economies. Journal of Economic Dynamics and Control 17, 953-969

[23] Imrohoroglu, A., 1989. Cost of Business Cycles with Indivisibilities and Liquidity Constraints. Journal of Political Econoomy, 97(6), 1364-1383.

[24] Imrohoroglu, S., Kitao, S., 2011. Social Security Reforms: Benefit Claiming, Labor Force Participation and Long-run Sustainability. American Economic Journal: Macroeconomics, forthcoming.

[25] Jeske, K., Kitao, S., 2009. U.S. Tax Policy and Health Insurance Demand: Can a Regressive Policy Improve Welfare? Journal of Monetary Economics, 56(2), 210-221.

[26] Joint Committee on Taxation, 2015. Estimates of Federal Tax Expenditures for Fiscal Years 2015-2019. Manuscript JCX-141R-15 
[27] Kaiser Family Foundation, 2009. Employer Health Benefits Survey. Available at http://ehbs.kff.org/2009.html

[28] Kaiser Family Foundation, 2011. Summary of New Health Reform Law. Available at www.kff.org/healthreform/upload/8061.pdf

[29] Kahn, J., Kronick, R., Kreger, M., Gans, D. 2005. The Cost of Health Insurance Administration in California: estimates for insurers, physicians, and hospitals. Health Affairs 24.

[30] Kennickel, A., 2006. Currents and Undercurrents: Changes in the Distribution of Wealth, 1989-2004. Mimeo, Federal Reserve Board.

[31] Kim, S., 2012. The Labor Supply and Welfare Effects of Early Access to Medicare through Social Security Disability Insurance. Mimeo, Ohio State University.

[32] Kopecky, K., Koreshkova, T., 2013. The Impact of Medical and Nursing Home Expenses on Savings. forthcoming at American Economic Journal: Macroeconomics.

[33] Ozkan, S., 2011. Income Differences and Health Care Expenditures over the Life Cycle. Mimeo, Federal Reserve Board.

[34] Pashchenko, S., Porapakkarm, P., 2013. Quantitative Analysis of Health Insurance Reform: Separating Regulation from Redistribution. Review of Economic Dynamics, 16: $383-404$.

[35] Pashchenko, S., Porapakkarm, P., 2015a. Welfare Costs of Reclassification Risk in the Health Insurance Market. Journal of Macroeconomics.

[36] Pashchenko, S., Porapakkarm, P., 2015b. Reducing Medical Spedning of the Publicly Insured. Mimeo, University of Georgia

[37] Pauly, 2001. Making Sense of a Complex System, Empirical Studies of EmploymentBased Health Insurance. International Journal of Health Care Finance and Economics.

[38] Prados, M., 2012. Health And Earnings Inequality Over The Life Cycle: The Redistributive Potential of Health Policies. Mimeo, Columbia University.

[39] Ross, D., Jarlenski, J., Artiga, S., Marks, C., 2009. A Foundation for Health Reform: Findings of a 50 State Survey of Eligibility Rules, Enrollment and Renewal Procedures, and Cost-Sharing Practices in Medicaid and CHIP for Children and Parents during 2009. Kaiser Commission on Mediaid and the Uninsured. 
[40] St-Amour, P., 2012. Life Cycle Responses to Medicare. Manuscript, University of Lausanne.

[41] Storesletten, K., Telmer, C., Yaron, Y., 2004. Consumption and Risk Sharing Over the Life Cycle. Journal of Monetary Economics 51(3), 609-633.

[42] Tauchen, G., Hussey, R., 1991. Quadrature-Based Methods for Obtaining Approximate Solutions to Nonlinear Asset Pricing Models. Econometrica 59(2), 371-396.

[43] Wolff, E., 2010. Recent Trends in Household Wealth in the United States: Rising Debt and the Middle-Class Squeeze - an Update to 2007. Levy Economics Institute of Bard College Working Paper No. 589.

[44] Young, E., 2010. Solving the Incomplete Markets Model with Aggregate Uncertainty Using the Krusell-Smith Algorithm and Non-Stochastic Simulations. Journal of Economic Dynamics and Control, 34(1), 36-41.

[45] Zhao, J. (2014). Social Security and the Rise in Health Spending. Journal of Monetary Economics, 64. 


\section{Appendix (for online publication)}

\section{A Calibration of the baseline model}

\section{A.1 Demographics, preferences and technology}

The conditional survival probabilities $\zeta_{t}$ were adjusted for the difference in medical expenses following Attanasio et al. (2011). The population growth rate was set to $1.35 \%$ to match the fraction of people older than 65 in the data.

The consumption share in the utility function $\chi$ is set to 0.6 , which is in the range estimated by French (2005). ${ }^{36}$ The parameter $\sigma$ is set to 5 , which corresponds to the risk-aversion over consumption equal to $3.4 .^{37}$ The discount factor $\beta$ is calibrated to match the aggregate capital output ratio of 3 . The labor supply of those who choose to work $(\bar{l})$ is set to 0.4

Fixed leisure costs of work $\phi_{t, e}$ are calibrated to match the employment profiles in each educational and health group. ${ }^{38}$ The fixed costs for people in good health $\phi_{1}(t, e)$ are assumed not to vary with age, whereas the additional fixed costs of people with bad health $\phi_{2}(t, e)$ are assumed to be a linear function of age. ${ }^{39}$

The Cobb-Douglas function parameter $\alpha$ is set at 0.33 , which corresponds to the capital income share in the US. The annual depreciation rate $\delta$ is calibrated to achieve an interest rate of $4 \%$ in the baseline economy. The total factor productivity $\mathrm{A}$ is set such that the total output equals one in the baseline model.

\section{A.2 Insurance status and medical expenditures}

In the MEPS, the question about the source of insurance coverage is asked retrospectively for each month of the year. A person is defined as having employer-based insurance if he reports having ESHI for at least eight months during the year. The same criterion is used when defining public insurance and individual insurance status.

Medical costs in the model correspond to the total paid medical expenditures in the MEPS dataset. These include not only out-of-pocket medical expenses but also the costs covered by insurers. In the calibration, medical expense shock is approximated by a 5 -state discrete Markov process. These 5 states are defined by dividing the medical

\footnotetext{
${ }^{36}$ Given that we have an indivisible labor supply, this parameter cannot be pinned down using a moment in the data.

${ }^{37}$ The relative risk aversion over consumption is given by $-c u_{c c} / u_{c}=1-\chi(1-\sigma)$.

${ }^{38} \mathrm{~A}$ person is defined as employed if he works at least 520 hours per year, earns at least $\$ 2,678$ per year in base year dollars (this corresponds to working at least 10 hours per week and earning a minimum wage of $\$ 5.15$ per hour), and does not report being retired or receiving Social Security benefits.

${ }^{39}$ The fixed costs of work are estimated jointly with the labor income process. The estimation of the labor income process is explained in more detail in section A.6.
} 
expenditures for each age into 5 bins, corresponding to the 30th, 60th, 90th and 99th percentiles. The value of medical expenses in each bin is a coefficient on a corresponding age dummy in the regression of medical expenses on a set of age and year dummies. The estimated coefficients were smoothed with a cubic function of age. ${ }^{40}$ The resulting profiles are shown in Figure (8).

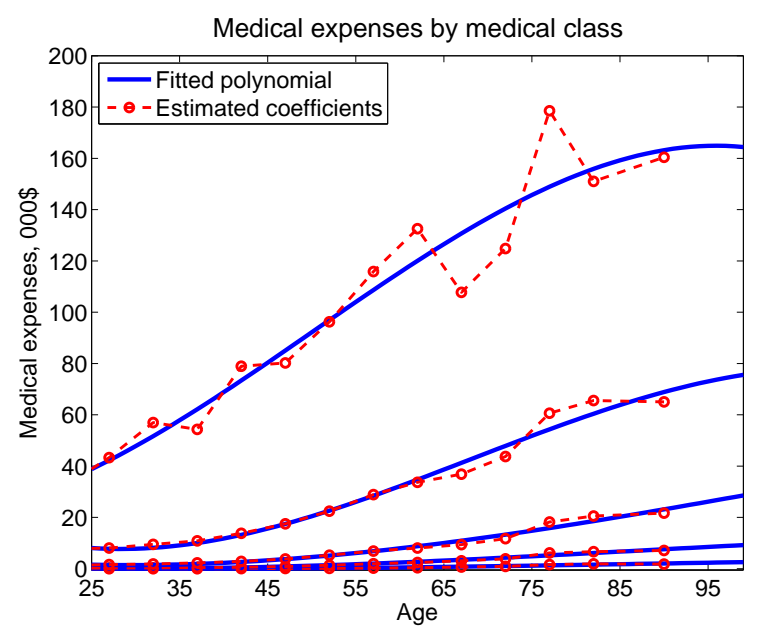

Figure 8: Medical expenses for each bin

The parameter $\overline{x_{t}}$ that separates people into different medical expenses categories is set to the 90th percentile of medical expenses distribution of the corresponding age. In other words, people whose medical expenses are in the lowest three bins are classified as healthy, whereas people whose medical expenses are in the highest two bins are classified as unhealthy. The transition matrix is constructed by measuring the fraction of people who move from one bin to another between two consecutive years separately for people of working age (25-64) and for retirees (older than 65).

The fraction of medical expenses covered by insurance policies $q\left(x_{t}, i_{t}\right)$ is estimated based on the MEPS. The fraction of medical spending covered by Medicare $q_{m e d}$ is set to 0.5, following Jeske and Kitao (2009) and Attanasio et al. (2011).

\section{A.3 Government}

The tax function $\mathcal{T}(y)$ takes the following form, as in Gouveia and Strauss (1994):

$$
\mathcal{T}(y)=a_{0}\left[y-\left(y^{-a_{1}}+a_{2}\right)^{-1 / a_{1}}\right]
$$

In this functional form, $a_{0}$ controls the marginal tax rate faced by the highest income

\footnotetext{
${ }^{40}$ The MEPS tends to underestimate the aggregate medical expenditures (Sing et al., 2002). To bring the average medical expenses computed from the MEPS in line with the corresponding statistics in the National Health Expenditure Account (NHEA), the estimated medical expenses were multiplied by 1.37 for people younger than 75 years old and by 1.93 for people older than 75 years old.
} 
group, $a_{1}$ determines the curvature of marginal taxes and $a_{2}$ is a scaling parameter. The parameters $a_{0}$ and $a_{1}$ are set to the original estimates in Gouveia and Strauss (1994), which are 0.258 and 0.768 , respectively. The parameter $a_{2}$ is used to balance the government budget in the baseline economy. The proportional income tax $\tau_{y}$ is set to $6.62 \%$ to match the fact that approximately $65 \%$ of tax revenues come from income taxes that are approximated in the calibration by the progressive function $\mathcal{T}(y)$. When considering policy experiments, we keep $a_{2}$ as in the baseline economy and adjust $\tau_{y}$ to balance the government budget.

The minimum consumption floor $\underline{c}$ is set to $\$ 2,700$, following the estimates of De Nardi et al. (2010). The Social Security replacement rates were set to $40 \%$ and $30 \%$ of the average labor income for people with low and high education, respectively, reflecting the progressivity of the system.

Medicaid eligibility rules were taken from the data. The income eligibility threshold for general Medicaid ( $y^{\text {cat }}$ ) is set to $64 \%$ of FPL, which is the median value for this threshold among all states in 2009. The income eligibility threshold for the Medically

Needy program $\left(y^{\text {need }}\right)$ and the asset test for this program $\left(k^{\text {pub }}\right)$ are set to $53 \%$ of FPL and $\$ 2,000$, respectively. These numbers are equal to the median values for the corresponding eligibility criteria in 2009 in the states that have the Medically Needy program.

The Medicare, Social Security and consumption tax rates were set to $2.9 \%, 12.4 \%$ and $5.67 \%$, respectively. The maximum taxable income for Social Security is set to $\$ 84,900$. The fraction of exogenous government expenses in GDP is $18 \%$.

\section{A.4 Insurance sector}

The share of the health insurance premium paid by the firm $(\psi)$ was chosen to match the aggregate ESHI take-up rate. The resulting number is $76.3 \%$. The proportional loads for group and individual insurance policies $(\gamma)$ is set to 1.11 (Kahn et al., 2005). The fixed costs of buying an individual policy $\pi$ is set to $\$ 23$ to match the aggregate fraction of people with individual insurance.

\section{A.5 Offer rate}

The probability of receiving an offer of ESHI coverage is a logistic function ${ }^{41}$ :

$$
\operatorname{Prob}_{t}=\frac{\exp \left(u_{t}\right)}{1+\exp \left(u_{t}\right)},
$$

\footnotetext{
${ }^{41} \mathrm{An}$ individual is defined as having an offer if any member of his HIEU reports having an offer in at least two of three interview rounds during a year. Household heads whose income was below $\$ 1,000$ were excluded when estimating the logistic regression.
} 
where the variable $u_{t}$ is an odds ratio that takes the following form:

$$
u_{t}=\eta_{0}^{e}+\eta_{1}^{e} \log \left(i n c_{t}\right)+\eta_{2}^{e}\left[\log \left(i n c_{t}\right)\right]^{2}+\eta_{3}^{e}\left[\log \left(i n c_{t}\right)\right]^{3}+\eta_{4}^{e} \mathbf{1}_{\left\{g_{t-1}=1\right\}}+\Theta^{e} D_{t}
$$

Here, $\eta_{0}^{e}, \eta_{1}^{e}, \eta_{2}^{e}, \eta_{3}^{e}, \eta_{4}^{e}$ and $\Theta^{e}$ are education-specific coefficients, inc $c_{t}$ is individual labor income (normalized by the average labor income), and $D_{t}$ is a set of year dummy variables. ${ }^{42}, 43$

\section{A.6 Labor income}

Households are divided into two educational groups: high-school dropouts and people with at least a high-school degree. The fraction of each group in the population is $15 \%$ and $85 \%$, respectively. Individuals with different education and health have different productivity, which is specified as follows:

$$
z_{t}^{e, x}=\lambda_{t}^{e, x} \exp \left(v_{t}\right) \exp \left(\xi_{t}\right)
$$

where $\lambda_{t}^{e, x}$ is the deterministic function of age, education and health, and

$$
\begin{gathered}
v_{t}=\rho v_{t-1}+\varepsilon_{t}, \quad \varepsilon_{t} \sim N\left(0, \sigma_{\varepsilon}^{2}\right) \\
\xi_{t} \sim N\left(0, \sigma_{\xi}^{2}\right)
\end{gathered}
$$

For the persistent shock $v_{t}, \rho$ is set to 0.98 and $\sigma_{\varepsilon}^{2}$ to 0.018 following the incomplete market literature (Storesletten et al. (2004); Hubbard et al. (1994); Erosa et al. (2011); French $(2005))$. The variance of the transitory shock $\left(\sigma_{\xi}^{2}\right)$ is set to 0.1 which is in the range estimated by Erosa et al (2011).

To identify the deterministic part of productivity $\lambda_{t}^{e, x}$, we need to take into account that in the data, we only observe labor income of workers and we do not know the potential income of non-workers. To address this problem, we use the method developed by French (2005). We start by estimating the labor income profiles of workers based on the MEPS dataset. We do this by running a regression of labor income on a set of age and year dummies to control for time effects. ${ }^{44}$ Then, we guess $\lambda_{t}^{e, x}$ and feed these productivity profiles into our model. After solving and simulating the model, we compute the average labor income profile of workers in our model and compare it with the income

\footnotetext{
${ }^{42}$ The model's counterpart of the variable $i n c_{t}$ is individual productivity divided by the average productivity $\left(z_{t}^{e, x} / \bar{z}\right)$.

${ }^{43}$ In all experiments, the offer probability is the same as in the baseline. Aizawa and Fang (2012) use an equilibrium search model to examine how firms offering ESHI would respond if the tax subsidy were removed. They find only a small change in the equilibrium offer rate.

${ }^{44}$ Household labor income is defined as the sum of wages and $75 \%$ of the income from business.
} 
profiles estimated from the data. We adjust $\lambda_{t}^{e, x}$ until the labor income profile generated by our model is the same as in the data for each health group.

\section{B The effect of tax exclusion reform on employment and insurance statistics}

Table 10 shows the change in the insurance and employment behavior as a result of the tax subsidy reform before the ACA. Table 11 shows these changes after the ACA.

\begin{tabular}{|l|c|c|c|c|c|c|}
\hline & \multicolumn{3}{|c|}{ Employment (\%) } & \multicolumn{3}{|c|}{ Insurance (\%) } \\
\hline & All & LE & HE & Unins & Indiv & MCD \\
\hline Baseline & 89.7 & 75.6 & 92.2 & 19.7 & 7.3 & 8.6 \\
1. No tax subsidy & 86.9 & 74.7 & 89.2 & 62.4 & 22.7 & 10.8 \\
Tax subsidy only to a certain group: & & & & & & \\
2. $\left(x_{t}=1\right.$ and age $\left.\leq 55\right)$ or $\left(x_{t}=2\right.$ and age $\left.\leq 43\right)$ & 88.9 & 75.3 & 91.4 & 20.8 & 7.7 & 9.1 \\
3. $x_{t}=1+$ age-adj CR & 88.9 & 75.5 & 91.3 & 18.1 & 7.5 & 9.1 \\
4. $x_{t}=1$ and income $<2^{*}$ FPL + age-adj CR & 89.5 & 76.3 & 91.8 & 17.3 & 7.3 & 8.5 \\
\hline
\end{tabular}

Table 10: The effects of tax subsidy reform before the ACA

\begin{tabular}{|l|c|c|c|c|c|c|}
\hline & \multicolumn{3}{|c|}{ Employment (\%) } & \multicolumn{3}{|c|}{ Insurance (\%) } \\
\hline & All & LE & HE & Unins & Indiv & MCD \\
\hline Post-ACA baseline & 89.1 & 79.8 & 90.8 & 8.9 & 18.5 & 10.1 \\
1. No tax subsidy & 88.3 & 79.9 & 89.8 & 31.1 & 24.2 & 10.4 \\
Tax subsidy only to a certain group: & & & & & & \\
2. $\left(x_{t}=1\right.$ and age $\left.\leq 55\right)$ or $\left(x_{t}=2\right.$ and age $\left.\leq 43\right)$ & 88.6 & 79.8 & 90.1 & 9.6 & 18.8 & 10.3 \\
3. $x_{t}=1+$ age-adj CR & 88.3 & 79.8 & 89.8 & 8.8 & 19.5 & 10.1 \\
4. $x_{t}=1$ and income $<2 *$ FPL + age-adj CR & 88.6 & 80.1 & 90.0 & 8.6 & 19.2 & 10.1 \\
\hline
\end{tabular}

Table 11: The effects of tax subsidy reform after the ACA

\section{Changes introduced by the ACA}

This section describes how the ACA provisions change the baseline model.

\section{C.1 Household problem}

After the reform, a working-age household may be subject to penalties if he remains uninsured or may receive subsidies to buy individual health insurance. In addition, more households will be eligible for Medicaid. The eligibility for subsidies and the Medicaid 
expansion depends on a household's total income $\left(y_{t}^{t o t}\right)$, whereas penalties are a function of the taxable income $\left(y_{t}\right)$. We can rewrite the budget constraint of a working-age household (4) in the following way:

$$
\begin{gathered}
k_{t}(1+r)+\widetilde{w} z_{t}^{e, x} l_{t}+T_{t}^{S I}+B e q_{e}+\operatorname{Sub}\left(y_{t}^{t o t}, i_{H}^{\prime}\right)=\left(1+\tau_{c}\right) c_{t}+k_{t+1}+ \\
x_{t}\left(1-q\left(x_{t}, i_{t}\right)\right)+P_{t}+\operatorname{Tax}+\operatorname{Pen}\left(y_{t}, i_{H}^{\prime}\right) .
\end{gathered}
$$

Here $S u b\left(y_{t}^{\text {tot }}, i_{H}^{\prime}\right)$ and $\operatorname{Pen}\left(y_{t}, i_{H}^{\prime}\right)$ are subsidies and penalties, respectively. A household with income above $400 \%$ of the Federal Poverty Line (FPL) cannot receive subsidies. People having income below $400 \%$ of FPL and receiving an ESHI offer are eligible for premium subsidies in the individual market only if their employee's contribution $(\bar{p})$ exceeds $9.5 \%$ of their total income. The subsidy structure ensures that individuals within a certain income category do not spend more than a certain fraction of their income on health insurance. More specifically, spending on individual insurance premiums is limited to the percentage of total income shown in Table $12 .{ }^{45}$

\begin{tabular}{|c|c|}
\hline \hline Maximum premium spending (\% of income) & Income categories (\% of FPL) \\
\hline 2.0 & $<133$ \\
3.5 & $133-150$ \\
5.2 & $150-200$ \\
7.2 & $200-250$ \\
8.8 & $250-300$ \\
9.5 & $300-400$ \\
\hline \hline
\end{tabular}

Table 12: Maximum spending on individual insurance as a percentage of total income after receiving subsidies

The income eligibility threshold for the general Medicaid program is increased to $133 \%$ of FPL. There are no changes in the Medically Needy program.

An uninsured person whose insurance premium in the individual market is less than $8 \%$ of his income must pay a penalty. The penalty is determined by

$$
\operatorname{Pen}\left(y_{t}, i_{H}^{\prime}\right)=\max \left\{0.025 y_{t}, \$ 695\right\} \quad \text { if } i_{H}^{\prime}=U
$$

\section{C.2 Insurance sector after the reform}

The reform imposes a heavy regulation on the individual insurance market. Insurance companies can no longer condition premiums on the current medical cost of individuals.

\footnotetext{
${ }^{45}$ The subsidy function specified in the ACA is slightly more complicated: for each income category, it specifies the range of maximum premium spending as a fraction of income. We approximate this range by selecting the midpoint of a corresponding interval. For example, the range for the income category $133-150 \%$ of FPL is $3-4 \%$, and we approximate it by the midpoint $3.5 \%$.
} 
The insurance premium of an individual of age $\widehat{t}$ will be determined by

$$
p_{I}(\hat{t})=(1+r)^{-1} \gamma \frac{\left(\int_{\mathbf{t}=\widehat{t}} \mathbf{1}_{\left\{i_{H}^{\prime}(\mathbf{s})=I\right\}} E M\left(x_{t}, t\right) \Gamma(\boldsymbol{s})\right)}{\int_{\mathbf{t}=\widehat{t}} \mathbf{1}_{\left\{i_{H}^{\prime}(\mathbf{s})=I\right\}} \Gamma(\boldsymbol{s})}+\pi .
$$

Thus, after the reform the individual market premium $p_{I}$ will be a function of age only.

\section{C.3 Government constraint}

We maintain the assumption that the government runs a balanced budget. This implies

$$
\begin{gathered}
\int\left[\operatorname{Tax}(\boldsymbol{s})+\tau_{c} c_{t}(\boldsymbol{s})\right] \Gamma(\boldsymbol{s})-G+\int_{t<R} \operatorname{Pen}\left(y_{t}, i_{H}^{\prime}\right) \Gamma(\boldsymbol{s})= \\
\int_{t \geq R}\left[s s_{e}+q_{\text {med }}\left(x_{t}\right) x_{t}-p_{\text {med }}\right] \Gamma(\boldsymbol{s})+\int T_{t}^{S I} \Gamma(\boldsymbol{s})+\int_{t<R} \mathbf{1}_{\left\{i_{H}^{\prime}=M\right\}} q\left(x_{t}, 1\right) x_{t} \Gamma(\boldsymbol{s}) \\
+\int_{t<R} S u b\left(y_{t}^{t o t}, i_{H}^{\prime}\right) \Gamma(\boldsymbol{s})
\end{gathered}
$$

The left-hand side now has an additional source of revenue - penalties from those unwilling to purchase insurance. The right-hand side has an additional expenditure - subsidies. To balance the government budget, we adjust $\mathcal{T}\left(y_{t}\right)$ to make it more progressive. ${ }^{46}$ More specifically, to achieve a balanced budget in the economy with the ACA provisions in place, we adjust the parameter $a_{0}$, which controls the marginal tax rate faced by the highest income group.

\section{Computational algorithm}

We solved for the steady state equilibrium of the baseline model as follows.

1. Guess an initial interest rate $r$, price in the group insurance market $p$, the amount the firm offering ESHI subtracts from the wage of their workers $c_{E}$, tax parameter $a_{2}$, and bequest $B e q_{e}{ }^{47}$

\footnotetext{
${ }^{46}$ More specifically, the reform increases the hospital insurance payroll tax on people with income above $\$ 200,000$ by $0.9 \%$ and imposes a $3.8 \%$ tax on unearned income for higher-income tax-payers (Kaiser Family Foundation, 2011). Our calibration strategy assumes a standard log-normal income process commonly used in the macro-literature, which cannot generate the empirical fraction of top earners. Because of this, we increase the progressivity of the general tax code to capture the main idea of financing the reform by taxing the rich more.

${ }^{47}$ In general, insurance markets in which firms are not allowed to risk-adjust premiums, as in the group market, can have multiple equilibriums. However, because the major part of the premium is contributed by the employer, people are less sensitive to the price of insurance; thus, the multiplicity of equilibriums
} 
2. Solve for the households' decision rules using backward induction. We evaluate the value function for points outside the state space grid using a Piecewise Cubic Hermite Interpolating Polynomial (PCHIP).

3. Given the policy functions simulate the households distribution using a nonstochastic method, as in Young (2010).

4. Using the distribution of households and policy functions, check whether the market clearing conditions and zero profit conditions for insurance firms hold, and whether the government budget balances. If not, update $r, p, c_{E}, a_{2}$, and $B e q_{e}$, and repeat Steps $1-3$.

The computation of the steady-state for the reformed economy is complicated by the fact that we now need to compute additional 40 prices (for each working age) in the individual community-rated market. We modified the algorithm above by guessing these 40 prices at Step 1 and updating them at Step 4.

becomes less of an issue. In particular, our equilibrium price tends to be invariant to the initial guess. 